\title{
Impact of gameplay vs. reading on mental models of social-ecological systems: a fuzzy cognitive mapping approach
}

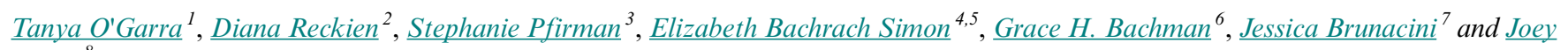
$\underline{\text { J. Lee }}^{8}$

\begin{abstract}
Climate change is a highly complex social-ecological problem characterized by system-type dynamics that are important to communicate in a variety of settings, ranging from formal education to decision makers to informal education of the general public. Educational games are one approach that may enhance systems thinking skills. This study used a randomized controlled experiment to compare the impact on the mental models of participants of an educational card game vs. an illustrated article about the Arctic social-ecological system. A total of 41 participants (game: $n=20$; reading: $n=21$ ) created pre- and post-intervention mental models of the system, based on a "fuzzy cognitive mapping" approach. Maps were analyzed using network statistics. Both reading the article and playing the game resulted in measurable increases in systems understanding. The group reading the article perceived a more complex system after the intervention, with overall learning gains approximately twice those of the game players. However, game players demonstrated similar learning gains as article readers regarding the climate system, actions both causing environmental problems and protecting the Arctic, as well as the importance of the base- and mid-levels of the food chain. These findings contribute to the growing evidence showing that games are important resources to include as strategies for building capacity to understand and steward sustainable social-ecological systems, in both formal and informal education.
\end{abstract}

Key Words: Arctic; climate change; fuzzy cognitive mapping; polar regions; serious games; systems thinking

\section{INTRODUCTION}

Climate change is a highly complex environmental problem characterized by system-type dynamics. Given this complexity, sustainable stewardship of social-ecological systems affected by climate change will require communication and problem solving that accounts for the dynamics of the system (Senge 1990, Richmond 1993, Maani 2013). Thinking in terms of the system rather than in terms of its component parts is broadly termed "systems thinking."

Despite the large literature dealing with systems thinking, there is a lack of agreement as to what systems thinking entails (Davidz et al. 2004, Maani and Maharaj 2004). There are numerous definitions as well as lists of systems thinking skills, each with a different focus (e.g., von Bertalanffy 1968, Gharajedaghi and Ackoff 1984, Senge 1990, Richmond 1993, Checkland 1999, Gharajedaghi 1999, Rechtin and Maier 2010, Ossimitz 2000). The definition provided by Moore et al. (2010: 5) suggests that systems thinking is "The ability to recognize, understand, and synthesize the interactions, and interdependencies in a set of components designed for a specific purpose." For this analysis, we use this working definition, albeit removing the reference to "design":

Systems thinking is the ability to recognize, understand, and synthesize the interactions, and interdependencies in a set of elements that form a coherent whole.

Scholars in the fields of learning sciences and education have long claimed that games are a potentially useful means for enhancing systems thinking skills (Dieleman and Huisingh 2006, Gee 2007, DeVane et al. 2010, Senge et al. 2012, Shute and Ke 2012, Storey and Butler 2013, Meadows et al. 2016). In particular, newer educational games are assumed to increase learning in ways that may not be achievable by other means, such as more traditional methods of documentaries, written text, or older learning games that tend to be drill and practice exercises for improving content knowledge (McGonigal 2011). By engaging participants in experiential learning within complex systems, games can deliver powerful experiences from new perspectives, which can support the development of systems thinking (Wu and Lee 2015). This is especially relevant to climate change learning (Deaton 2015, Wu and Lee 2015, Meya and Eisenack 2018), as many people perceive climate change as psychologically distant and abstract (e.g., Gifford 2011, van der Linden et al. 2015). As noted by Ouariachi et al. (2017), climate games can be used to overcome barriers to climate change learning and action by decreasing psychological distance, making climate change more real and memorable, and providing a sense of agency.

The present study aims to add to our understanding of the potential for games to enhance climate systems thinking by evaluating the impact of an educational card game about climate change in the Arctic on participants' mental models of the system. Mental models can be understood as internal (i.e., mental) representations of external dynamic systems (Doyle and Ford 1998) that embody causal relationships between components of the system (Levy et al. 2018). We assess people's mental models to identify the extent to which they perceive the complex interactions and interdependencies between elements of the Arctic climate system.

Participants' mental models were elicited using cognitive maps, which are visual representations of knowledge, involving subcomponents (so-called "concepts") linked by arrows

${ }^{1}$ Middlesex University, London, UK, ${ }^{2}$ University of Twente, Faculty of Geo-Information Science and Earth Observation, The Netherlands, ${ }^{3}$ Arizona State University, Phoenix, Arizona, USA, ${ }^{4}$ Goodman Research Group, Inc., Cambridge, Massachusetts, USA, ${ }^{5}$ SAE International, Warrendale, Pennsylvania, USA, ${ }^{6}$ Johns Hopkins Bloomberg School of Public Health, ${ }^{7}$ Michigan State University, Michigan, USA, ${ }^{8}$ Teachers College, Columbia University, New York, New York, USA 
indicating the causal direction of relationship between concepts. Cognitive maps can be understood as visual representations of people's mental models (Axelrod 1976, Gray et al. 2014, Gray 2018, Levy et al. 2018). Mental models derived from cognitive maps are used as measures of systems thinking ability in Levy et al. (2018). As with Levy et al. (2018), we assess systems thinking by way of a network tool that analyzes people's mental models about a system. Levy et al. (2018) examine the cognitive maps of thought leaders in (agricultural) sustainability to measure the extent to which each map captures fundamental causal patterns of sustainability. Their hypothesis is that more complex forms of causal structure in mental models are associated with higher levels of systems thinking. Similarly, we investigate participants' mental model structure using indices of network statistics (described in detail below) to derive insights about the extent to which they perceive the Arctic social-ecological system in terms of complex interactions and interdependencies. Indeed, most studies exploring systems thinking interventions do so by examining changes in the mental models of the participants (e.g., LanganFox et al. 2000, Doyle et al. 2008, Plate 2010, Mahajan et al. 2019).

Complexity of participants' mental models was assessed using "fuzzy cognitive mapping" (FCM), which is an extension of cognitive mapping. However, whereas cognitive mapping shows the causal direction between concepts, FCM adds information about the strength of causality between concepts, lending quantitative rigor to the analysis of cognitive maps (Reckien et al. 2011, 2013, Reckien 2014). It provides a robust framework for testing and analyzing game-based learning of systems due to its ability to represent individuals' mental models via concept and weighted causal relations (Luo et al. 2010). Network approaches such as FCM have been used in other studies to quantify learning effects (Teodoro et al. 2021), although to the best of our knowledge, FCM specifically has not been used to assess gamebased learning.

Using a randomized controlled experiment in the lab, impacts of the educational card game are evaluated in comparison wth a "control." For this, we use an illustrated article - representing a more conventional approach to learning. The game under evaluation (EcoChains: Arctic Crisis (EcoChains)), was designed by Joey Lee and Stephanie Pfirman, under the project Polar Learning and Responding: PoLAR Climate Change Education Partnership, to teach players about climate change through the lens of the Arctic marine ecosystem (Lee 2020, Turrin et al. 2020, Pfirman et al. 2021). The "control" article was written so as to contain similar content to the game (see Methods for details.)

Participants were randomly assigned to either play the game or read the article; FCM outcomes were compared between the game ("treatment") and the article ("control") groups. Participants' mental models associated with the Arctic social-ecological climate system were elicited before and after the interventions (see Append. 1 for exact wording of the prompt), allowing us to examine how perceptions about the system, its components, and the interactions between them are influenced by the interventions.

Our analysis is grounded in theories of psychological distance, such as Construal Level Theory, which posits that experiences are mainly appraised based on the spatial, temporal, or social distance to an individual (Trope and Liberman 2010). Psychologically closer objects or events are internalized in concrete terms, whereas objects and events that are psychologically more distant are internalized in more abstract terms (Margolin and Markowitz 2018). These construal patterns have downstream effects; for example, evidence suggests a detailed and concrete thinking style can encourage people to appraise and feel connected to information (Markowitz et al. 2018). For a pressing and complex issue such as climate change, which for many still remains a psychologically distant concept (Gifford 2011, van der Linden et al. 2015), game play can bring the issue psychologically closer to participants, which in turn can enhance the ability to perceive the complexity of climate system and the effects of problematic environmental behavior on this system (Meya and Eisenack 2018).

As distinguished by Gosen and Washbush (2004), we focus on differential learning and skill development from the intervention rather than performance within the intervention. We assume that learning would occur after both game play and reading, but we hypothesize that game play would result in larger learning gains about the complexity of the social-ecological system. This is because participants will experience environmental impacts more tangibly and intensively through the immersive experience of game play as they make choices to respond to changing circumstances, making the social-ecological system of the Arctic psychologically closer. However, we anticipate this potential for enhanced learning would be moderated by the fact that participants have to learn to play an unfamiliar game.

This study makes several key contributions to the literature. Firstly, it adds to the nascent literature on the impacts of games on systems thinking. The earliest of these (Torres 2009, DeVane et al. 2010) used ethnographic discourse approaches to examine game players' ability to think in terms of "systems" as a result of playing video games, and both found that games have potential to enhance systems thinking. More recently, Whalen et al. (2018) found that players of In the Loop exhibited increased understanding of system interconnections among various issues, stakeholders, sectors, and disciplines. In the study that is closest to ours in design, Waddington and Fennewald (2018) used concept mapping to compare the impact of a climate-focused game vs. a non-climate game on participants' mental models; they found that the climate game generated more learning about systemic climate concepts than the non-climate game; however, the analysis did not use network indices or examine the structure of people's mental representations of the system. To the best of our knowledge, ours is the first study to identify the impact of a game on systems thinking using structural network indices to examine the change in participants' mental models.

Our study also contributes to the broader literature on the impacts of games on learning. In general, most studies find that games (including computer games and serious games) assist with knowledge acquisition, as well as planning, behavior change, and collaborative skills (see Connolly et al. 2012, Boyle et al. 2016, and Hainey et al. 2016 for systematic reviews). Recent analyses of new social-ecological games/simulations, including Aztec Chess, TRUE GRASP, and The Flow of Peasant Lives, found that the games improved participants' understanding of how to strategize feasible actions to manage and mitigate socialecological stress (García-Barrios et al. 2017, 2020, Braasch et al. 
2018). In one of the earlier studies of climate change games, Fouquet (2003) found that participants in a "carbon trading" roleplaying game reported a longer-lasting memory of the experience compared with most lectures on the subject. Our study contributes to this important literature by confirming the potential of games to enhance learning.

As a final note, we acknowledge that systems thinking may not fully embody the "messy" and unruly processes that can characterize complex social-ecological systems, such as feedback interactions that are not entirely systemic and coherent (Taylor 2005). Thus, while respecting the complexity and "messiness" inherent in social-ecological systems, systems thinking is mostly about distinguishing systemic relationships within systems (White 1995, Kok 2009).

\section{METHODS}

Adults from the general public were invited to participate in a research study in Boston (see description of recruitment procedures in Pfirman et al. 2021). Fifty participants were recruited, and due to no-shows, 41 completed the study (game: $n$ $=21$; reading: $n=20$ ). The average age of participants was 35 years, ranging from 18 to 67 years. There were more women $(63 \%)$ than men $(37 \%)$. We did not collect race/ethnicity, education, or income data because randomization of participants to intervention groups was expected to resolve any potential confounding effects from these factors (Fisher 1935, Rubin 1974) (see Limitations section). Political party affiliation information, however, was collected because the issue of climate change is politically polarized (Hamilton 2008, 2011, 2021, McCright and Dunlap 2011), so we were interested in identifying the political composition of our study participants. The participants identified mostly as Democrats (66\%), Independents $(20 \%)$, or "other" $(14 \%)$. None of the participants identified as Republicans. The political affiliations of the study participants largely reflect the recruitment region, where $54 \%$ were registered as Democrats, $39 \%$ were not enrolled in a political party, $7 \%$ were registered as Republicans, and fewer than $1 \%$ each were registered as Independent or Green-Rainbow Party (Carraggi 2016).

Based on participants' volunteered availability and no other criteria, we facilitated six group sessions of up to eight or ten participants over the course of two weekends. Participants were randomly assigned to one of two groups: game (treatment) or article (control), and each person participated in only one session. The study setup for both groups was as follows: first, all participants completed an online survey. This was followed by instructions about how to produce their individual maps, after which they had 15-20 min. to complete their first map (Map 1). This was then followed by the intervention (described below). After the intervention, participants engaged in a brief unfacilitated discussion and completed an online postintervention survey, after which they were given 10-15 min. to revise their maps (thus producing Map 2). See Append. 1 for the instructions used to guide the mapping exercise. The sessions concluded with a 5-min. discussion facilitated by the moderator.

Questions regarding the experience were displayed on a slide, and the facilitator concluded the session by reading a script explaining the purpose of the study and noting that there would be a followup survey and a more detailed debrief of the full study (Pfirman et al. 2021). Note that because we wanted to replicate the informal educational setting of playing or reading at home with family and friends, rather than a classroom, we chose not to conduct a content-oriented debriefing immediately following the in-person session as is recommended to enhance learning from games in formal educational settings (Petranek 1994, Kriz 2010, Wouters et al. 2013, Meadows et al. 2016, Flood et al. 2018, Waddington and Fennewald 2018).

The online pre-intervention survey collected data on gender, age, and political party affiliation. We also collected data on existing knowledge of and attitudes toward climate change and the Arctic, and repeated these questions in the post-intervention survey, so as to test changes in attitudes and perceived knowledge. These data are analyzed in Pfirman et al. (2021). Additionally, we conducted a follow-up online survey 4 weeks after the intervention. This follow-up survey did not include a FCM component, and so we will not discuss it further in this analysis.

\section{Treatment}

Participants in the treatment group watched a 6-min. instructional video about the rules and goals of the game (https://youtu.be/ npii9FYaMT8). They then proceeded to play one round of the game in groups of three to four for approximately $40 \mathrm{~min}$., with the aid of a facilitator who was present to answer questions that arose during game play. Participants played the game until the session time was called; they did not play the game more than once.

EcoChains: Arctic Crisis is a card game designed for two to four players (free download available at https://globalfutures.asu.edu/ ecochains-arcticfutures/). Players act as stewards, building Arctic food webs by drawing species cards and placing them in predatorprey relationships. Players begin the game with seven sea ice cards in their reserve, plus one ice algae paired with one ice zooplankton, and one phytoplankton paired with one krill in their initial food web setup. They take turns randomly drawing species, event, or action cards from a central deck. Species cards are placed in predator-prey relationships to build out their food webs. Although some Arctic marine species are reliant on sea ice, others are not, and this reliance is designated by the number of sea ice cards required to support the species in a small white circle on the card (Fig. 1). When carbon pollution event cards are drawn, all players are required to melt two sea ice cards by flipping them to the ocean side. When too much ice is gone to support the icedependent species in the player's food web, those species have to be removed along with any prey that is dependent on them. These species can migrate to other player's webs if they have a sufficient web structure to support them.

Playing action cards, such as reducing carbon emissions and carbon capture and sequestration, brings some sea ice back for all players (and provides two points to the person who played the card), so ice-dependent species can be reintroduced to player food webs when subsequently drawn from the central deck. Strategy develops through game play, as players learn to reorganize their food webs and structure predator-prey relationships to maximize diversity (each species card in play is worth one point) and minimize dependence on sea ice. By allowing them to experience and respond to changes due to global warming and other negative impacts on Arctic ecosystems, the game teaches players the components of an Arctic marine ecosystem, the reliance of some 
Fig. 1. In an attempt to replicate how an educational text would usually teach about interactions in a food web, an illustration of a food web was included in the article used as the control intervention. (A) Food web illustration from illustrated article with arrows indicating predation relationships. (B) Sample of game player experience in treatment intervention showing layout of cards in game. Species cards are linked in predator-prey relationships extending from the base of the food web up to the apex predators. The small white circles on the bottom right of some species cards denotes their ice dependency, indicating that they can only be added to the food web when there is sufficient ice. Note that the food web illustration in the article is more complete than what most players experienced in one round of game play.
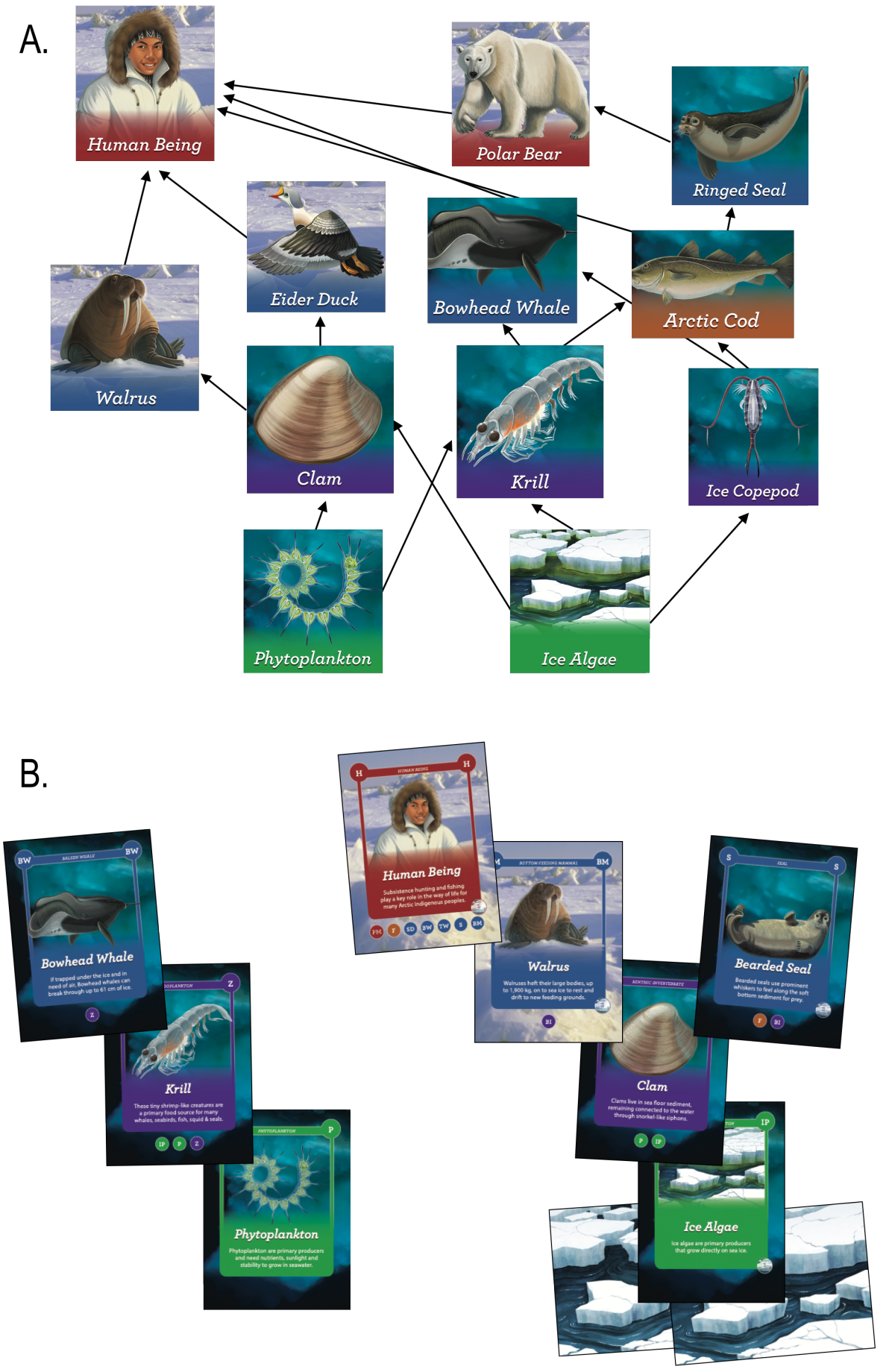
Table 1. Key FCM Indices

\begin{tabular}{|c|c|}
\hline Abbreviation & Description \\
\hline Nodes & Number of concepts on map (denoted $\mathrm{N}) \dagger$ \\
\hline Connections & Number of relationships between nodes $($ denoted $\mathrm{C}) \dagger$ \\
\hline $\mathrm{C} / \mathrm{N}$ & $\begin{array}{l}\text { Ratio of connections to nodes. Indicates degree of connectivity between concepts; Higher ratios indicate the connections between } \\
\text { concepts are denser } \dagger\end{array}$ \\
\hline Density & Density—indicates perceived connectivity between nodes $[\mathrm{C} /[\mathrm{N}(\mathrm{N}-1)]] \dagger$ \\
\hline Centrality & $\begin{array}{l}\text { Centrality of different nodes - sum of the weights of an N's incoming and outgoing influences. Indicates which Ns are important/ } \\
\text { central in different individual's maps. Useful to help identify whether the perceived centrality of key concepts such as "sea ice" or } \\
\text { "fossil fuels" increases between pre-test and post-test. }+\end{array}$ \\
\hline Outdegree & $\begin{array}{l}\text { Outdegree is the sum of absolute value of weights of influences from a particular node. Measure of influence of a particular } \mathrm{N} \text { on } \\
\text { other N. } \neq\end{array}$ \\
\hline Indegree & $\begin{array}{l}\text { Indegree is the sum of absolute value of weights influencing a particular node. Measure of dependency of a particular node on } \\
\text { other nodes. } \$\end{array}$ \\
\hline Receivers & $\begin{array}{l}\text { Number of receiver nodes - indicates number of nodes that have positive "in-degree" and zero "out-degree," i.e., are influenced by } \\
\text { other components of the map. Indicator of complexity of thinking_-"many receiver concepts indicate that the cognitive map } \\
\text { considers many outcomes and implications that are a result of the system" (Özesmi and Özesmi 2004) (denoted R). } \dagger\end{array}$ \\
\hline Transmitters & $\begin{array}{l}\text { Number of transmitter nodes - indicates number of nodes that have positive "out-degree" and zero "in-degree," i.e., nodes that } \\
\text { actively influence other components of the map. Indicates top-down, hierarchical thinking. Causal arguments not well elaborated } \\
(\text { denoted T). } \dagger\end{array}$ \\
\hline
\end{tabular}

species on sea ice, the impacts of climate change on the ecosystem, and actions that can be taken to reduce global warming and, therefore, sea ice melt. The 150-card EcoChains: Arctic Crisis deck included 17 species (multiple cards for each, totaling 80 cards), nine events (four carbon pollution/ice melt, one rapid sea ice loss, two overharvesting, one invasive killer whales, one ocean acidification), eight actions (four greenhouse gas emissions reductions, one carbon capture and sequestration, two protect a species, two protect a sea), 32 sea ice, and 16 goal cards that provided additional points for achieving specific species combinations.

\section{Control}

In order to isolate the effect of the game on our main dependent variables (i.e., the fuzzy cognitive mapping indices; Table 1), we also collected data from control groups. The control intervention was an illustrated article specifically adapted for this study to include information similar to that on the EcoChains cards, including incorporation of some images also used on the cards (see Append. 2: Control Text). Participants spent about $20 \mathrm{~min}$. reading the article individually, with the others in the same room. Our decision to use an article-based format for the control was based on our consideration of conventional sources of information for the general adult population. Once out of the formal learning environment of high school or college, adults obtain most of their information from informal sources such as television, newspapers, magazine articles, and more recently, online sources (Young 2015). We opted to use the magazine article format for the control, because it allowed us to design the content to match the content of EcoChains as closely as possible. In order to simulate how a magazine or other educational text would usually illustrate food web relationships, a diagram was included in the article that showed predator-prey relationships between species (Fig. 1; Append. 2). We explore in the Limitations section how this figure may have influenced participant FCMs.

\section{Fuzzy Cognitive Mapping Exercise Implementation}

Before the intervention, to obtain cognitive maps from participants, the first step in the process involved explaining how to draw a mental model map, using completely unrelated content as an example (See Append. 1). Following the explanation, participants were handed a large 11" x 17" sheet of paper and a black lead pencil and asked to each write along the left-hand side all the concepts they could think of under the following headings, which were read out in turn:

- Arctic marine and sea-ice ecosystems, including the species and inhabitants of these ecosystems.

- All the different factors that negatively affect the health of Arctic marine and sea-ice ecosystems, their species, and inhabitants.

- All the different factors that positively affect the health of Arctic marine and sea-ice ecosystems, their species, and inhabitants.

Participants were asked to put their pencils down when they were satisfied with their list of concepts. Once all participants had drafted their list of concepts, they were asked to draw their maps. This was a facilitated process, which involved them drawing their concepts in the center of the paper and drawing arrows between them to represent relationships between concepts and the direction of the relationship. Connections in cognitive maps may be read as "may lead to" (Brightman 2000). They then gave the connections a positive or negative sign and a strength of relationship ranging from -3 (strong negative relationship) to +3 (strong positive relationship). A negative relationship indicates that increases in one concept lead to decreases in the linked concept. A positive relationship indicates that increases in one concept lead to increases in the linked concept. Participants were asked to put their pencils down when they were satisfied with their maps. Participants' maps were collected by the facilitator before the intervention began. 
After the intervention, participants were handed back their original maps, together with a different colored pencil from the one they used previously. The purpose of using different colored pencils was to allow the investigators to identify changes in the maps (between Map 1 (pre-intervention) and Map 2 (postintervention). Participants were first reminded that the maps illustrate their thinking about the health of Arctic marine and sea-ice ecosystems, and then were asked to adjust the maps based on what they had learned from playing the game or reading the article. They were told, if they wished to delete anything, to cross it out, as we are interested in what they thought before they played the game/read the article. On average they took about $15 \mathrm{~min}$. to complete the first map, and $10 \mathrm{~min}$. to complete the second map. See Append. 1 for the facilitator script used for the FCM exercises.

\section{Fuzzy Cognitive Mapping Analysis}

The FCM maps were translated to adjacency matrices for analysis and analyzed using indices grounded in mathematical graph theory and network statistics (e.g., link density, indegree, outdegree). Doing so enables the comparison of structure of individual and/or aggregated FCMs (Özesmi and Özesmi 2004, Reckien 2014) between treatment and control groups.

Adjacency matrices were in the form $\mathrm{A}(\mathrm{D})=$ [aij] (Harary et al. 1965), where all the concepts in the map are listed both on the vertical axis and horizontal axis to form a square matrix. When a connection exists between two concepts (cause on the vertical axis; consequence on the horizontal axis) the value is coded in the respective intersecting cell of the square matrix (using the "strength" indicator ranging from -3 to +3 ).

Using this approach, we created two matrices for each respondent, one for Map 1 (pre-intervention) and one for Map 2 (postintervention; Fig. 2), which include:

Fig. 2. Example of a fuzzy cognitive map made by a participant. Black writing indicates initial concepts, green writing shows concepts added after treatment. This map shows that, after treatment, the participant added three new concepts and five new connections to the map. Inspection of the new additions shows that "overharvesting" has both incoming and outgoing connections, whereas "ice algae" and "phytoplankton" only have incoming connections, indicating positive "in-degree" and zero "out-degree".

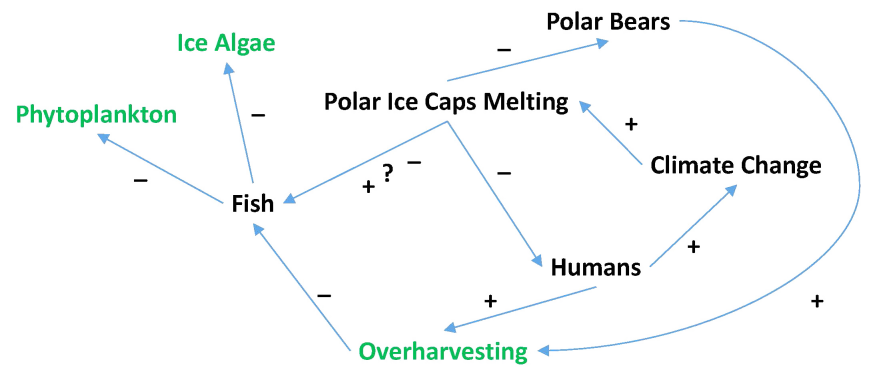

1. All nodes on $x$ and $y$ axis of matrix

2. All connections between nodes (i.e., presence of relationship, its valence and strength) indicated in the intersecting cell between those concepts.
Fuzzy cognitive mapping indices (Table 1) were calculated for each individual matrix using FCMappers (http://www.fcmappers. net/joomla/). We use the most common indices representing complexity in networks, as defined by Olazabal and Reckien (2015). Each index described in Table 1 represents a specific aspect of knowledge or understanding, with some indices (e.g., receiver concepts) highlighting complexity in thinking. Many receiver concepts indicate an awareness about how the many factors that make up the system interact to generate outcomes. This suggests a more holistic understanding of the implications of the system, which in FCM is considered indicative of complexity of thinking (Özesmi and Özesmi 2004).

\section{Statistical Analysis}

An increased level of systems' thinking skills in FCM is assumed to be demonstrated through increased complexity of mental maps, i.e., a change in network indices, such as number of concepts and number of links between concepts. In particular, the number of receivers and the number of connections are assumed to prove increased systems' thinking skills (see Table 1).

To identify the relative impact of game play (treatment) vs. reading (control) on the overall complexity of participants' mental maps, we calculate changes in FCM network statistic indices (the "maplevel indices", outlined in Table 1) between Map 1 and Map 2 for control and treatment participants separately, and compare these changes using Mann Whitney non-parametric U-tests as well as independent sample two-tailed t-tests. The null hypothesis for all tests is that the change in the FCM indices between Map 2 and Map 1 is equal between the treatment and control.

Analysis of the impact of the interventions on specific concepts (nodes) within participants' maps, uses "node-level indices" (Table 1). To compute changes in these indices, we have imputed a value of zero for all concepts that were not included in Map 1 but later added to Map 2 by any individual participant. For example, if an individual did not include "ice" in Map 1, but later added it to Map 2, we assume the node-level indices (centrality, outdegree, and indegree) relating to this concept have a value of zero in Map 1. This allows for estimation of the change in the weight and influence of key concepts.

We also present paired two-tailed t-tests and (non-parametric) Wilcoxon sign-rank tests comparing Map 1 and Map 2 indices within control and treatment groups. These tests (found in Append. 3) complement the main results, by showing the withingroup impact of the interventions on participants' mental models.

\section{RESULTS}

\section{Comparing Control and Treatment Groups}

The first step in analyzing data from randomized experiments involves identifying whether randomization was successful. Randomization ensures that the characteristics of participants that may influence the outcome are distributed between treatment and control groups so that any outcome of differences can be assumed to be attributable to the treatment. In this experiment, the key characteristics of interest are those relating to systems thinking about the Arctic social-ecological environment. We anticipate that, if randomization was implemented successfully, control and treatment groups should have equivalent baseline levels of systems thinking as indicated by Map 1. 
Table 2. Structural Analysis $(n=41)$. Figures in parentheses are standard deviations.

\begin{tabular}{lllc}
\hline \hline & Control $(n=20)$ & Game $(n=21)$ & $\mathrm{H}_{0}: \Delta$ Control $=\Delta$ Game \\
\cline { 2 - 3 } & $\Delta$ Map 2-Map 1 & $\Delta$ Map 2-Map 1 & Indep. t-test $p$ value \\
\hline Number of concepts (nodes) & $4.75(2.05)$ & $2.57(2.08)$ & 0.0017 \\
Number of connections & $12.55(5.92)$ & $4.47(2.82)$ & 0.0025 \\
Ratio of connections to nodes & $0.38(0.41)$ & $0.10(0.27)$ & 0.0000 \\
Density & $-0.05(0.04)$ & $-0.03(0.06)$ & 0.0164 \\
Number of transmitter nodes & $0.5(1.24)$ & $0.76(1.37)$ & 0.8962 \\
Number of receiver nodes & $0.7(0.98)$ & $0.24(1.18)$ & 0.7929 \\
Number of unconnected nodes & $0.15(1.04)$ & $0.00(1.30)$ & 0.0160 \\
\hline
\end{tabular}

To assess whether this is the case, we compare baseline systems thinking levels between groups using the FCM indices (see Table A4.1 in Append. 4). Results indicate that baseline systems thinking levels between the two groups are not statistically different. This, along with analyses that revealed no significant differences in demographic information collected (age, gender, political party affiliation), affirms that our samples are not systematically biased in any way between the two groups, and randomization was successful (see Methods above).

\section{Frequency of Concepts and Concept Type}

Table 2 presents mean changes in FCM indices between Map 1 and Map 2 and compares the level of change in FCM indices between the control and treatment interventions. This will help identify the relative influence of the two interventions on participants' knowledge levels and the complexity of their understanding about climate change in the Arctic socialecological system.

Although a simpler conceptual map can be an expression of a deeper understanding expressed more concisely, we follow Levy et al. (2018) in interpreting more complex maps as exhibiting awareness of complexity. Given that climate change is a highly complex system-involving multiple interdependent and interacting factors - we would expect that learning would lead to maps that more closely represent these multiple factors, and their interactions and interdependencies.

Results show that both reading the article and playing the game resulted in more complex maps (as evidenced by increases across almost all FCM indices), suggesting that both interventions positively influenced knowledge about concepts associated with social-ecological aspects of climate change in the Arctic, and the relations between them. Table A3.1 in Append. 3 confirms that most of these within-subject increases are significant for both control and treatment groups. However, Table 2 shows that the article was significantly more effective than the game in terms of the number of nodes and connections that participants added to their maps. For example, the control group added 1.84 more concepts (ratio between $\Delta$ Map 2-Map 1 between control and treatment) than the treatment group, and 2.80 more connections. We also note that the article had a greater impact on the ratio of connections to nodes, showing that the control group perceived a denser network of connections between concepts after the intervention, compared with the treatment group.

With regard to all other FCM indices, the game and the article had similar positive effects on participants' thinking about and assumed understanding of climate change and the Arctic social- ecological system. The ratio of the changes in the FCM indices for the game, to the changes in the indices for the article, was about $50 \%$ on average, suggesting that learning from the game was about half that of learning from the article.

\section{Frequency of Concepts per Subject Category}

This section considers the content of the concepts (nodes) generated by participants for their maps. In order to make the analysis of the large number of generated concepts manageable, they have been condensed into 12 broad categories (see Fig. 3 and Append. 5). Concept categories are based on expert judgement of the system, i.e., authors of this paper and developers of the game. As noted in Özesmi and Özesmi (2004), it is typical to reduce the total number of concepts in order to make analysis meaningful. The clustering of concepts into subject categories makes it easier to compare the outcome of the interventions across the two groups.

Fig. 3. Concept frequency in participant maps before and after the interventions. "Human actions causing ..." is an abbreviation for "Human actions causing environmental problems."
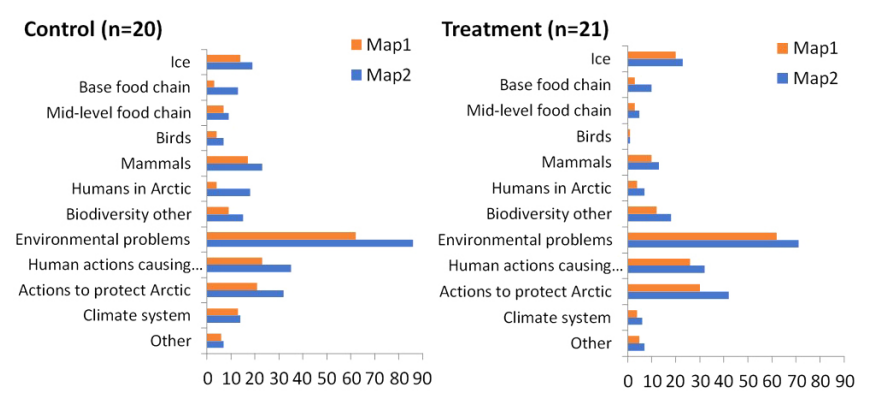

Fig. 3 shows the distribution of concepts in each of the 12 broad categories for treatment and control group, divided by Map 1/ Map 2.

Overall, the most frequently mentioned concepts belong to the category "environmental problems,"; this is true for both Map 1 and Map 2 in treatment and control groups. The control group in particular added more concepts that were grouped into "environmental problems" after reading the article, suggesting the article had a greater impact on participants' perception of the range of environmental problems in the Arctic compared with the game. 
Table 3. Centrality for concept categories. Figures in parentheses are standard deviations.

\begin{tabular}{|c|c|c|c|c|}
\hline & \multirow{2}{*}{$\begin{array}{l}\text { Control } \\
(n=20) \\
\Delta \text { Map 2-Map 1 }\end{array}$} & \multirow{2}{*}{$\begin{array}{l}\text { Treatment } \\
(n=21) \\
\Delta \text { Map 2-Map 1 }\end{array}$} & \multicolumn{2}{|c|}{$\mathrm{H}_{0}: \Delta$ Control $=\Delta$ Game } \\
\hline & & & MW test $p$ value & Indep. t-test $p$ value \\
\hline Ice & $2.00(1.62)$ & $1.09(1.40)$ & $0.0363^{*}$ & 0.0567 \\
\hline Base food chain & $2.48(1.20)$ & $1.70(0.84)$ & 0.1256 & 0.0911 \\
\hline Mid-level food chain & $2.52(1.81)$ & $1.13(1.07)$ & 0.1088 & 0.1466 \\
\hline Birds & $1.62(1.59)$ & $-0.67(-)$ & 0.1221 & + \\
\hline Mammals & $1.66(1.22)$ & $0.43(0.53)$ & $0.0006^{*}$ & $0.0016^{*}$ \\
\hline Humans in Arctic & $2.11(1.99)$ & $0.71(0.56)$ & 0.0941 & 0.0830 \\
\hline Biodiversity other & $2.42(1.34)$ & $0.67(1.25)$ & $0.0010^{*}$ & $0.0005^{*}$ \\
\hline Environmental problems & $1.30(1.50)$ & $0.55(1.41)$ & $0.0016^{*}$ & $0.0018^{*}$ \\
\hline $\begin{array}{l}\text { Human actions causing environ } \\
\text { problems }\end{array}$ & $1.12(1.71)$ & $0.63(0.93)$ & 0.2487 & 0.1480 \\
\hline Actions to protect Arctic & $0.99(1.23)$ & $0.60(0.86)$ & 0.53 & 0.1158 \\
\hline Climate system & $1.00(1.12)$ & $1.17(0.55)$ & 0.4755 & 0.7320 \\
\hline Other & $0.48(0.74)$ & $-0.43(1.58)$ & 0.5486 & 0.1953 \\
\hline
\end{tabular}

\section{Strength of Connections of Networks}

Different concepts have different types and levels of influence on other concepts (described in Table 1). Specifically, their centrality (sum of indegree and outdegree, i.e., sum of the absolute value of ingoing and outgoing arrows) provides some indication of which nodes are particularly important in participants' mental models of the Arctic (Table 3). In the context of the present study, we are particularly interested in identifying whether the treatment intervention (game) affected the relative influence of concepts relating to environmental problems, actions to protect the Arctic, and broad awareness of climate system aspects within individual maps compared with the control intervention.

For the control group, the concept categories for "ice," "mammals," "biodiversity other," and "environmental problems" showed a significantly greater increase in centrality after the intervention (Table 3), indicating that the article increased the perceived importance of these concepts. Compared with the article (control), the game had no effect on the centrality of any concepts.

Given that the centrality of each concept is a function of the total indegree and outdegree of each concept, these results can be explored in more depth by observing the change in the outdegree and indegree of each concept. Overall, both interventions have increased the understanding of how key factors in the Arctic ecosystem depend on others (i.e., the indegree); on the other hand, the interventions have had minimal effects on the understanding of how key factors influence other factors (i.e., the outdegree) (see Append. 3, Tables A3.3, A3.4). Tables 4 and 5 present results showing how the treatment (game) compared with the article in terms of increasing the outdegree and indegree of key concepts.

Results show that the article (control) is more effective than the game in increasing the outdegree and indegree of various key concepts, the most important of which is classed broadly as "environmental problems." As noted, we are particularly interested in examining whether the game can enhance understanding of how environmental problems in Arctic socialecological systems are linked with other factors, and how actions to resolve these are integrated in their mental models.
This study suggests that, although the game is less effective than the article in terms of increasing the weight and influence given to key concepts - such as environmental problems, ice (except for indegree), mammals (except for outdegree), and "other biodiversity" - it is similarly effective at increasing the importance given to the climate system, actions to protect the Arctic, human actions causing environmental problems, and base-level and midlevel food chains.

\section{DISCUSSION}

Using a randomized controlled experiment in the lab, we evaluated the differential impact of the game EcoChains: Arctic Crisis; compared with traditional learning via reading an illustrated article on participants' mental models of climaterelated aspects of the Arctic marine social-ecological system. To assess the structure of participant's mental models, we employed FCM, a participatory interview and analysis method for depicting and analyzing human perception of a given system (Reckien 2014, Olazabal and Reckien 2015).

Results show that both reading the illustrated article and playing the card game increased the complexity of participants' mental models. However, reading was roughly twice as effective as game play in terms of number of concepts and connections added to cognitive maps after the intervention. For example, the control group added on average 1.84 more concepts than did the treatment group. Nonetheless, even just a one-time experience of playing an unfamiliar game, with all the challenges this entails in terms of learning the rules, resulted in similar increases in perceived importance of concepts classed as "actions that cause environmental problems" as well as "actions that protect against them." These are critical concepts relating to agency vis à vis climate change; increasing agency is essential to stimulate climate action and, at the same time, serves to enhance systems thinking by reducing psychological distance, which in turn leads to less generalized and abstract mental models. Even though the system representation in the game was less formal and a slightly different experience for each participant, we find that they still came away with an understanding of important aspects of the Arctic marine social-ecological system. 
Table 4. Outdegree for concept categories. Figures in parentheses are standard deviations.

\begin{tabular}{|c|c|c|c|c|}
\hline & \multirow{2}{*}{$\begin{array}{l}\text { Control } \\
(n=20) \\
\Delta \text { Map 2-Map 1 }\end{array}$} & \multirow{2}{*}{$\begin{array}{l}\text { Treatment } \\
(n=21) \\
\Delta \text { Map 2-Map } 1\end{array}$} & \multicolumn{2}{|c|}{$\mathrm{H}_{0}: \Delta$ Control $=\Delta$ Game } \\
\hline & & & MW test $p$ value & Indep. t-test $p$ value \\
\hline Ice & $1.54(1.39)$ & $0.62(1.03)$ & $0.0081 *$ & $0.0178^{*}$ \\
\hline Base food chain & $1.13(1.22)$ & $0.47(0.69)$ & 0.1139 & 0.1401 \\
\hline Mid-level food chain & $1.45(1.54)$ & $0.73(0.87)$ & 0.3824 & 0.3621 \\
\hline Birds & $0.14(0.26)$ & $0.00()$. & 0.5677 & $\dagger$ \\
\hline Mammals & $0.39(0.62)$ & $0.13(0.26)$ & 0.2221 & 0.1578 \\
\hline Humans in Arctic & $0.31(0.66)$ & $0.38(0.52)$ & 0.4676 & 0.8128 \\
\hline Biodiversity other & $0.78(1.01)$ & $0.09(0.60)$ & $0.0177 *$ & $0.0215^{*}$ \\
\hline Environmental problems & $0.69(1.15)$ & $0.30(0.99)$ & $0.0234^{*}$ & $0.0231 *$ \\
\hline $\begin{array}{l}\text { Human actions causing environ } \\
\text { problems }\end{array}$ & $0.80(1.41)$ & $0.33(0.60)$ & 0.1580 & 0.0889 \\
\hline Actions to protect Arctic & $0.78(1.19)$ & $0.48(0.75)$ & 0.4749 & 0.1939 \\
\hline Climate system & $0.57(1.02)$ & $0.44(0.50)$ & 0.7089 & 0.7760 \\
\hline Other & $0.48(0.74)$ & $-0.57(1.23)$ & 0.1514 & 0.0771 \\
\hline
\end{tabular}

Although we focused on exploring game impact in an informal setting, others have noted that supplementing game play with additional instruction and debriefing enhances learning (Petranek 1994, Kriz 2010, Wouters et al. 2013, Meadows et al. 2016, García-Barrios et al. 2017, Flood et al. 2018, Waddington and Fennewald 2018). Therefore, future studies should analyze the types of systems learning gains that are achieved with and without supplemental instruction, for example having participants read the illustrated article as well as play the game, with and without debriefing, and with and without repeat game play.

\section{LIMITATIONS}

Several caveats must be taken into account regarding this study. The number of participants is limited. Although this is often the case in experimental studies due to the logistics of implementing interventions that have controls as well as treatments (see also Gosen and Washbush 2004), ideally we would have a larger number of responses to analyze. Also, future studies are needed to understand the impact on learning of participant familiarity with games and potential pre-dispositions to learning from them. The recruitment language used in this study solicited people "to help with the development of a new educational game" (Pfirman et al. 2021).

Other factors that could influence differential receptiveness to learning through game play vs. reading are participant race/ ethnicity, education, and income (Nicole 2016, Martindale and Weiss 2019, Pfirman et al., 2021). We did not collect these data as the randomization of participants to intervention groups was expected to resolve any potential confounding effects from these factors (Fisher 1935, Rubin 1974). However, in hindsight, it would have been useful to collect these data to examine influences on learning and the development of systems thinking.

A related factor is that the more structured and familiar delivery of information in the article likely led to greater advances in systems thinking skills than the more novel, unpredictable, and variable experience of the unfamiliar game. In the game, initial attention had to focus on learning game play as well as content, and the cards were revealed in random order. Once people invest in learning a game, they are likely to play it again, whereas articles are unlikely to be read again. Eighty-one percent of game players in this study said that they would be likely to buy the game so they could play again. After rules are learned, in repeat game play, more attention can be paid to thinking about the concepts and other content-related information in the game. Repeated play also allows participants to experience alternative outcomes and think about winning strategies, thus becoming more knowledgeable of causes and effects (e.g., Petranek 1994, Eisenack 2013, Wouters et al. 2013, Garcia-Barrios et al. 2017, Pfirman et al. 2021). Therefore, we anticipate that repeat game play would enhance systems learning gains, as also indicated by several study participants:

- "I think the game could be a good introduction to the issues of climate change. Going over the issues and then playing the game again could help reinforce what's going on."

- "I think if I played it a few more times, it would have stuck much more."

We recognize that including the complete food web illustration (Fig. 1) in the article set a stringent comparison for differential learning from the game and may have been a factor in the more effective representations of learning by the article readers. We included the illustration because any article designed to teach about systems interactions would include such a figure. Study participants were likely primed to recognize concept maps by the initial exercise of creating a mental model map themselves. When those who read the article then saw the illustration, they may have focused on it, noticing features that were different from the one that they drew initially. In contrast, those playing the game may not have made the direct connection between the informal way their cards were linked (Fig. 1) and their mental model map. If this were the case, it would be likely that the "human being" category would show statistically significant differences between the two groups. A human being is prominently featured at the top of the food web (Fig. 1), but there are only three human being cards within the 150 EcoChains card deck, so their impact in the game would seem to be diluted. Indications that this may be the 
Table 5. Indegree for concept categories. Figures in parentheses are standard deviations.

\begin{tabular}{|c|c|c|c|c|}
\hline & \multirow{2}{*}{$\begin{array}{l}\text { Control } \\
(n=20) \\
\Delta \text { Map 2-Map 1 }\end{array}$} & \multirow{2}{*}{$\begin{array}{l}\text { Treatment } \\
(n=21) \\
\Delta \text { Map 2-Map 1 }\end{array}$} & \multicolumn{2}{|c|}{$\mathrm{H}_{0}: \Delta$ Control $=\Delta$ Game } \\
\hline & & & MW test $p$ value & Indep. t-test $p$ value \\
\hline Ice & $0.46(0.69)$ & $0.46(0.75)$ & 0.8391 & 0.9712 \\
\hline Base food chain & $1.36(0.70)$ & $1.23(0.96)$ & 0.6174 & 0.7140 \\
\hline Mid-level food chain & $1.07(0.83)$ & $0.40(0.55)$ & 0.1394 & 0.1318 \\
\hline Birds & $1.48(1.48)$ & $-0.67()$. & 0.1244 & $\dagger$ \\
\hline Mammals & $1.28(0.86)$ & $0.31(0.58)$ & $0.0014 *$ & $0.0009 *$ \\
\hline Humans in Arctic & $1.80(1.90)$ & $0.33(0.58)$ & $0.0169 *$ & 0.0600 \\
\hline Biodiversity other & $1.64(1.27)$ & $0.57(1.02)$ & $0.0079 *$ & $0.0116^{*}$ \\
\hline Environmental problems & $0.60(0.67)$ & $0.25(0.66)$ & $0.0033^{*}$ & $0.0014^{*}$ \\
\hline $\begin{array}{l}\text { Human actions causing environ } \\
\text { problems }\end{array}$ & $0.32(0.59)$ & $0.29(0.58)$ & 0.6466 & 0.8209 \\
\hline Actions to protect Arctic & $0.21(0.39)$ & $0.12(0.46)$ & 0.3984 & 0.3852 \\
\hline Climate system & $0.43(0.82)$ & $0.72(0.91)$ & 0.3838 & 0.4854 \\
\hline Other & $0.00(0.00)$ & $0.14(0.54)$ & 0.5338 & 0.4980 \\
\hline
\end{tabular}

case are the facts that more people in the control group did include human beings in Map 2 than those who played the game, a difference that was marginally significant (Table 3, MW .09), and the difference in indegree representation - which is most similar to the illustration (Fig. 1) - is significant (Table 5, MW .02).

Finally, this study only assessed changes in mental models of the system immediately after the intervention. Over time, the relative changes in systems thinking may differ between individuals who read the article vs. those who played the game. The Pfirman et al. (2021) analysis found that EcoChains game-players had better longer term (4-week) retention of new species knowledge compared with those who read the article. It is possible that this "stickier" learning of content associated with game play may also be found with regard to systems thinking.

\section{CONCLUSION}

As we engage in developing sustainable responses to climate change, we need to build capacity for social-ecological systems thinking. This experimental study of gains in systems thinking indicates that both reading an illustrated text and playing an unfamiliar game one time increased systems learning. Although we also found that reading the text was more effective in improving participants' systems thinking overall than one time playing of an unfamiliar game, the game players demonstrated similar learning gains regarding the climate system, actions to protect the Arctic, human actions causing environmental problems, and the base and mid-level food chain. This is important because games reach different people than do articles. As we seek to broaden discourse on social-ecological aspects of climate change beyond those already engaged (Turrin et al. 2020, Pfirman et al. 2021), even the ca. $50 \%$ overall systems learning gains from the game add to enhancing capacity. In particular, the fact that game play and active participation in it resulted in similar learning gains as reading in increasing awareness of the influence of actions is important as we seek to inform decision making regarding management and stewardship. These findings add to the growing literature recommending that games be included in our portfolio of formal and informal education strategies to build capacity for sustaining social-ecological systems.
Future studies may concentrate on tradeoffs (see Galafassi et al. 2017, Braasch et al. 2018), synergies, non-linear effects, and other opportunities and/or difficult decisions that are implicit in the management of social-ecological systems in the Arctic and elsewhere, and the contribution of FCMs, the EcoChains game, and other games and learning tools to studying those aspects. Although these were not the topic of this experiment, it is worth investigating to what level these and other learning environments may facilitate reflections about these management decisions.

\section{HUMAN SUBJECTS}

This research was approved by Columbia University's Institutional Review Board: IRB-AAAF2862.

Responses to this article can be read online at: https://www.ecologyandsociety.org/issues/responses. php/12425

\section{Acknowledgments:}

This research is based primarily on work supported by the National Science Foundation under grant numbers 1239783 and 1928235. Any opinions, findings, and conclusions or recommendations expressed in this material are those of the author $(s)$ and do not necessarily reflect the views of the National Science Foundation. D.R. wants to acknowledge support by the German Research Foundation (RE 2927/2-1). T.O. and D.R.: research design and data collection for this article was undertaken while at the Center for Research on Environmental Decisions, Columbia University, New York, New York 10027, USA.

\section{Data Availability:}

The datalcode that support the findings of this study are openly available in Figshare at https:/ldoi.org/10.6084/m9.figshare. Ethical approval for this research study was granted by Columbia University's Institutional Review Board: IRB-AAAF2862 


\section{LITERATURE CITED}

Axelrod, R. 1976. Structure of decision: the cognitive maps of political elites. Princeton University Press, Princeton, New Jersey, USA. https://doi.org/10.1515/9781400871957

Boyle, E. A., T. Hainey, T. M. Connolly, G. Gray, J. Earp, M. Ott, T. Lim, M. Ninaus, C. Ribeiro, and J. Pereira. 2016. An update to the systematic literature review of empirical evidence of the impacts and outcomes of computer games and serious games. Computers and Education 94:178-192. https://doi.org/10.1016/j. compedu.2015.11.003

Braasch, M., L. García-Barrios, S. Cortina-Villar, E. HuberSannwald, and N. Ramírez-Marcial. 2018. TRUE GRASP: actors visualize and explore hidden limitations of an apparent win - win land management strategy in a MAB reserve. Environmental Modelling and Software 105:153-170. https://doi.org/10.1016/j. envsoft.2018.03.022

Brightman, J. 2000. What's in a name? Cognitive mapping, mind mapping, concept mapping. Insights into qualitative data analysis. Scolari, Sage Publications, London, UK. [online] URL: https:// banxia.com/dexplore/resources/training-materials/

Carraggi, M. 2016. How many democrats, republicans in Boston? Here's a breakdown of the 382,946 registered voters in Boston. Patch Media, Boston, Massachusetts, USA. [Online] URL: https://patch.com/massachusetts/boston/how-many-democratsrepublicans-boston-0

Checkland, P. 1999. Systems thinking. Pages 45-56 in W.L. Currie, and B. Galliers, editors. Rethinking management information systems. Oxford University Press, Oxford, UK.

Connolly, T. M., E. A. Boyle, E. MacArthur, T. Hainey, and J. M. Boyle. 2012. A systematic literature review of empirical evidence on computer games and serious games. Computers and Education 59(2):661-686. https://doi.org/10.1016/j.compedu.2012.03.004

Davidz, H., D. Nightingale, and D. Rhodes. 2004. Enablers, barriers, and precursors to systems thinking development: the urgent need for more information. In Proceedings, International Conference on Systems Engineering Research (CSER) / International Council on Systems Engineering (INCOSE), Las Vegas, Nevada, USA.

Deaton, J. 2015. Can games be a game-changer for climate? (Oped). LiveScience, Future US Inc., New York, New York, USA. [Online] URL: https://www.livescience.com/53207-can-climatechange-game-change-minds.html

DeVane, B., S. Durga, and K. Squire. 2010. 'Economists who think like ecologists': reframing systems thinking in games for learning. E-Learning and Digital Media 7(1):3-20. https://doi. org/10.2304/elea.2010.7.1.3

Dieleman, H., and D. Huisingh. 2006. Games by which to learn and teach about sustainable development: exploring the relevance of games and experiential learning for sustainability. Journal of Cleaner Production 14(9-11):837-847. https://doi.org/10.1016/j. jclepro.2005.11.031
Doyle, J. K., and D. N. Ford. 1998. Mental models concepts for system dynamics research. System Dynamics Review: the Journal of the System Dynamics Society 14(1):3-29. https://doi. org/10.1002/(SICI)1099-1727(199821)14:1<3::AID-SDR140>3.0. CO;2-K

Doyle, J. K., M. J. Radzicki, and W. S. Trees. 2008. Measuring change in mental models of complex dynamic systems. Pages 269-294 in H. Qudrat-Ullah, M. Spector, and P. Davidsen, editors. Complex decision making. Springer, Berlin, Heidelberg, Germany. https://doi.org/10.1007/978-3-540-73665-3 14

Eisenack, K. 2013. A climate change board game for interdisciplinary communication and education. Simulation and Gaming 44(2-3):328-348. https://doi.org/10.1177/1046878112452639

Fisher, R. A. 1935. The design of experiments. Oliver and Boyd, Edinburgh and London, UK. https://doi.org/10.1136/bmj.1.3923.554a

Flood, S., N. A. Cradock-Henry, P. Blackett, and P. Edwards. 2018. Adaptive and interactive climate futures: systematic review of "serious games" for engagement and decision-making. Environmental Research Letters 13(6): 063005. https://doi. org/10.1088/1748-9326/aac1c6

Fouquet, R., 2003. The carbon trading game. Climate Policy 3(2): S143-S155. https://doi.org/10.1016/j.clipol.2003.09.011

Galafassi, D., T. M. Daw, L. Munyi, K. Brown, C. Barnaud, and I. Fazey. 2017. Learning about social-ecological trade-offs. Ecology and Society 22(1): 2. https://doi.org/10.5751/ ES-08920-220102

García-Barrios, L., J. Cruz-Morales, J. Vandermeer, and I. Perfecto. 2017. The Azteca chess experience: learning how to share concepts of ecological complexity with small coffee farmers. Ecology and Society 22(2): 37. https://doi.org/10.5751/ ES-09184-220237

García-Barrios, L., T. Rivera-Núñez, J. Cruz-Morales, J. Urdapilleta-Carrasco, E. Castro-Salcido, I. Peña-Azcona, O. Martínez-López, A. López-Cruz, M. Morales, and J. Espinoza. 2020. The flow of peasant lives: a board game to simulate livelihood strategies and trajectories resulting from complex rural household decisions. Ecology and Society 25(4): 48. https://doi. org/10.5751/ES-11723-250448

Gee, J. 2007. Learning and games, Pages 21-40 in K. Salen, editor. The ecology of games. The John D. and Catherine T. MacArthur Foundation Series on Digital Media and Learning, MIT Press, Cambridge, Massachusetts, USA.

Gharajedaghi, J. 1999. Iterative design, the third generation of systems thinking. Proceedings of the 43rd Meeting of the International Society for the Systems Sciences. Asilomar Conference Center, Pacific Grove, California, USA.

Gharajedaghi, J., and R. L. Ackoff. 1984. Mechanisms, organisms and social systems. Strategic Management Journal 5(3):289-300. https://doi.org/10.1002/smj.4250050308

Erratum: In the original PDF version of this paper the reference list was truncated. The entire reference list was added on 27 May 2021. 
Gifford, R., 2011. The dragons of inaction: psychological barriers that limit climate change mitigation and adaptation. American Psychologist 66(4):290-302. https://doi.org/10.1037/a0023566

Gosen, J., and J. Washbush. 2004. A review of scholarship on assessing experiential learning effectiveness. Simulation and Gaming 35(2):270-293. https://doi.org/10.1177/1046878104263544

Gray, S., 2018. Measuring systems thinking. Nature Sustainability 1(8):388-389. https://doi.org/10.1038/s41893-018-0121-1

Gray, S. A., E. Zanre, and S. R. Gray. 2014. Fuzzy cognitive maps as representations of mental models and group beliefs. Pages 29-48 in E. I. Papageorgiou, editor. Fuzzy cognitive maps for applied sciences and engineering. Springer, Berlin, Heidelberg, Germany. https://doi.org/10.1007/978-3-642-39739-4 2

Hainey, T., T. M. Connolly, E. A. Boyle, A. Wilson, and A. Razak. 2016. A systematic literature review of games-based learning empirical evidence in primary education. Computers and Education 102:202-223. https://doi.org/10.1016/j.compedu.2016.09.001

Hamilton, L. C. 2008. Who cares about polar regions? Results from a survey of U.S. public opinion. Arctic, Antarctic, and Alpine Research 40(4):671-678. https://doi.org/10.1657/1523-0430(07-105) [hamilton]2.0.co:2

Hamilton, L. C., 2011. Education, politics and opinions about climate change evidence for interaction effects. Climatic Change 104(2):231-242. https://doi.org/10.1007/s10584-010-9957-8

Hamilton, L. C. 2021. Two kinds of polar knowledge. Journal of Geoscience Education 69(2):106-112. https://doi.org/10.1080/10$\underline{899995.2020 .1838849}$

Harary, F., R. Z. Norman, and D. Cartwright. 1965. Structural models: an introduction to the theory of directed graphs. Wiley, New York, New York, USA.

Kok, K. 2009. The potential of fuzzy cognitive maps for semiquantitative scenario development, with an example from Brazil. Global Environmental Change 19(1):122-133. https://doi. org/10.1016/j.gloenvcha.2008.08.003

Kriz, W. C. 2010. A systemic-constructivist approach to the facilitation and debriefing of simulations and games. Simulation and Gaming 41(5):663-680. https://doi.org/10.1177/1046878108319867

Langan-Fox, J., S. Code, and K. Langfield-Smith. 2000. Team mental models: techniques, methods, and analytic approaches. Human Factors 42(2):242-271. https://doi.org/10.1518/001872000779656534

Lee, J. J. 2020. Games can teach about climate change and motivate ecofriendly actions. School Library Journal. [online] URL: https://www.slj.com/?detailStory=games-teach-about-climatechange-and-can-alter-behavior

Levy, M. A., M. N. Lubell, and N. McRoberts. 2018. The structure of mental models of sustainable agriculture. Nature Sustainability 1(8):413-420. https://doi.org/10.1038/s41893-018-0116-y

Luo, X., X. Wei, and J. Zhang. 2010. Guided game-based learning using fuzzy cognitive maps. IEEE Transactions on Learning Technologies 3(4):344-357. https://doi.org/10.1109/TLT.2010.26
Maani, K. E. 2013. Decision-making for climate change adaptation: a systems thinking approach, National Climate Change Adaptation Research Facility, Griffith University, Gold Coast, Queensland, Australia. [Online] URL: https://apo.org.au/ node/34598

Maani, K. E., and V. Maharaj. 2004. Links between systems thinking and complex decision making. System Dynamics Review: the Journal of the System Dynamics Society 20(1):21-48. https:// doi.org/10.1002/sdr.281

Mahajan, S. L., L. Glew, E. Rieder, G. Ahmadia, E. Darling, H. E. Fox, M. B. Mascia, and M. McKinnon. 2019. Systems thinking for planning and evaluating conservation interventions. Conservation Science and Practice 1(7): 44. https://doi. org/10.1111/csp2.44

Margolin, D., and D. M. Markowitz. 2018. A multitheoretical approach to big text data: comparing expressive and rhetorical logics in Yelp reviews. Communication Research 45(5):688-718. https://doi.org/10.1177/0093650217719177

Markowitz, D. M., R. Laha, B. P. Perone, R. D. Pea, and J. N. Bailenson. 2018. Immersive virtual reality field trips facilitate learning about climate change. Frontiers in Psychology 9: 2364. https://doi.org/10.3389/fpsyg.2018.02364

Martindale, R. C., and A, M. Weiss. 2019. "Taphonomy: Dead and fossilized": a new board game designed to teach college undergraduate students about the process of fossilization. Journal of Geoscience Education 68(3):1-21. https://doi.org/10.1080/10899995.2019.1693217

McCright, A. M., and R. E. Dunlap. 2011. The politicization of climate change and polarization in the American public's views of global warming, 2001-2010. The Sociological Quarterly 52 (2):155-194. https://doi.org/10.1111/j.1533-8525.2011.01198.x

McGonigal, J. 2011. Reality is broken: why games make us better and how they can change the world. Penguin, New York, New York, USA.

Meadows, D., L. B. Sweeney, and G. M. Mehers. 2016. The climate change playbook: 22 systems thinking games for more effective communication about climate change. Chelsea Green Publishing, Chelsea, Vermont, USA.

Meya, J. N., and K. Eisenack. 2018. Effectiveness of gaming for communicating and teaching climate change. Climatic Change 149(3):319-333. https://doi.org/10.1007/s10584-018-2254-7

Moore, S. M., M. A. Dolansky, M. Singh, P. Palmieri, and F. Alemi. 2010. The systems thinking scale. Case Western Reserve University, Cleveland, Ohio, USA.

Nicole, H. 2016. Survey results \#1: who are we? The Daily Worker Placement [Online] URL: http://dailyworkerplacement.com/2016/ 02/19/survey-results-1-who-are-we/

Olazabal, M., and D. Reckien. 2015. Fuzzy cognitive mapping: applications to urban environmental decision-making. Pages 148-176 in M. Ruth, editor. Handbook of research methods and applications in environmental studies. Edward Elgar, Cheltenham, UK. https://doi.org/10.4337/9781783474646.00013 
Ossimitz, K. G. 2000. The development of systems thinking skills using system dynamics modeling tools. Universität Klagenfurt, Institut für Mathematik, Statistik und Didaktik der Mathematik, Klagenfurt am Wörthersee, Austria. [Online] URL: http:// webdoc.sub.gwdg.de/ebook/e/gdm/1996/ossimitz.pdf

Ouariachi, T., M. D. Olvera-Lobo, and J. Gutiérrez-Pérez. 2017. Analyzing climate change communication through online games: development and application of validated criteria. Science Communication 39(1):10-44. https://doi.org/10.1177/1075547016687998

Özesmi, U., and S. L. Özesmi. 2004. Ecological models based on people's knowledge: a multi-step fuzzy cognitive mapping approach. Ecological Modelling 176(1-2):43-64. https://doi. org/10.1016/j.ecolmodel.2003.10.027

Petranek, C. 1994. A maturation in experiential learning: principles of simulation and gaming. Simulation and Gaming 25 (4):513-523. https://doi.org/10.1177/1046878194254008

Pfirman, S., T. O’Garra, E. Bachrach Simon, J. Brunacini, D. Reckien, J. J. Lee, and E. Lukasiewicz. 2021. "Stickier" learning through gameplay: an effective approach to climate change education. Journal of Geoscience Education 69(2):192-206. https:// doi.org/10.1080/10899995.2020.1858266

Plate, R. 2010. Assessing individuals' understanding of nonlinear causal structures in complex systems. System Dynamics Review 26(1):19-33. https://doi.org/10.1002/sdr.432

Rechtin, E., and M. W. Maier. 2010. The art of systems architecting. CRC Press, Boca Raton, Florida, USA. https://doi. org/10.1109/6.158642

Reckien, D. 2014. Weather extremes and street life in Indiaimplications of fuzzy cognitive mapping as a new tool for semiquantitative impact assessment and ranking of adaptation measures. Global Environmental Change 26:1-13. https://doi. org/10.1016/j.gloenvcha.2014.03.005

Reckien, D., M. Wildenberg, and M. Bachhofer. 2013. Subjective realities of climate change: how mental maps of impacts deliver socially sensible adaptation options. Sustainability Science 8 (2):159-172. https://doi.org/10.1007/s11625-012-0179-z

Reckien, D., M. Wildenberg, and K. Deb. 2011. Understanding potential climate change impacts and adaptation options in Indian megacities. Pages 15-34 in K. Otto-Zimmermann, editor. Resilient cities: cities and adaptation to climate changeproceedings of the Global Forum 2010. Volume 1. Springer, Dordrecht, The Netherlands. https://doi.org/10.1007/978-94-007-0785-6_3

Richmond, B. 1993. Systems thinking: critical thinking skills for the 1990s and beyond. System Dynamics Review 9(2):113-133. https://doi.org/10.1002/sdr.4260090203

Rubin, D. B. 1974. Estimating causal effects of treatments in randomized and nonrandomized studies. Journal of Educational Psychology 66(5):688-701. https://doi.org/10.1037/h0037350

Senge, P. M. 1990. The fifth discipline: the art and practice of the learning organization. Doubleday Business, New York, New York, USA. https://doi.org/10.1002/pfi.4170300510
Senge, P. M., N. Cambron-McCabe, T. Lucas, B. Smith, and J. Dutton. 2012. Schools that learn (updated and revised): a fifth discipline fieldbook for educators, parents, and everyone who cares about education. Crown Business, New York, New York, USA.

Shute, V. J., and F. Ke. 2012. Games, learning and assessment. Pages 43-58 in D. Ifenthaler, D. Eseryel, and X. Ge, editors. Assessment in game-based learning: foundations, innovations, and perspectives. Springer, New York, New York, USA. https://doi. org/10.1007/978-1-4614-3546-4 4

Storey, B. and J. Butler, 2013. Complexity thinking in PE: gamecentred approaches, games as complex adaptive systems, and ecological values. Physical Education and Sport Pedagogy 18 (2):133-149. https://doi.org/10.1080/17408989.2011.649721

Taylor, P. 2005. Unruly complexity: ecology, interpretation, engagement. University of Chicago Press, Chicago, Illinois, USA and London, UK. https://doi.org/10.7208/chicago/97802267903$\underline{98.001 .0001}$

Teodoro, J. D., C. Prell, and L. Sun. 2021. Quantifying stakeholder learning in climate change adaptation across multiple relational and participatory networks. Journal of Environmental Management 278(2): 111508. https://doi.org/10.1016/j. jenvman.2020.111508

Torres, R. J. 2009. Learning on a 21 st century platform: gamestar mechanic as a means to game design and systems-thinking skills within a nodal ecology. New York University, New York, New York, USA.

Trope, Y., and N. Liberman. 2010. Construal-level theory of psychological distance. Psychological Review 117(2): 440. https:// doi.org/10.1037/a0018963

Turrin, M., S. Pfirman, and L. Hamilton. 2020. Polar fun and games. Current: The Journal of Marine Education 34(1):9-15. https://doi.org/10.5334/cjme.43

van der Linden, S., E. Maibach, and A. Leiserowitz. 2015. Improving public engagement with climate change: five "best practice" insights from psychological science. Perspectives on Psychological Science 10(6):758-763. https://doi.org/10.1177/17$\underline{45691615598516}$

von Bertalanffy, L. 1968. General system theory: foundations, development, applications. George Braziller, New York, New York, USA. https://doi.org/10.1109/TSMC.1974.4309376

Waddington, D. I., and T. Fennewald. 2018. Grim FATE: learning about systems thinking in an in-depth climate change simulation. Simulation and Gaming 49(2):168-194. https://doi. org/10.1177/1046878117753498

Whalen, K. A., C. Berlin, J. Ekberg, I. Barletta, and P. Hammersberg. 2018. "All they do is win": lessons learned from use of a serious game for circular economy education. Resources, Conservation and Recycling 135:335-345. https://doi.org/10.1016/ j.resconrec.2017.06.021

White, D. 1995. Application of systems thinking to risk management. Management Decision 33(10):35-45. https://doi. org/10.1108/EUM0000000003918 
Wouters, P., C. van Nimwegen, H. van Oostendorp, and E. D. van Der Spek. 2013. A meta-analysis of the cognitive and motivational effects of serious games. Journal of Educational Psychology 105(2): 249. https://doi.org/10.1037/a0031311

Wu, J. S., and J. J. Lee. 2015. Climate change games as tools for education and engagement. Nature Climate Change 5(5):413-418. https://doi.org/10.1038/nclimate2566

Young, E. 2015. How millennials get news: Inside the habits of America's first digital generation. NORC Centre for Public Affairs Research and American Press Institute, Chicago, Illinois, USA. [Online] URL: http://www.americanpressinstitute.org/wp-content/ uploads/2015/03/How-Millennials-Get-News-Media-Insight-ProjectMarch-2015-FINAL.pdf 
Appendix 1. Master facilitator text

MENTAL MODEL MAPPING ACTIVITY

\section{Part 1: Pre-intervention/control (same for EcoChains game \& control groups)}

\section{$\underline{\text { Facilitator Guide }}$}

Participants are given a mapping sheet, a grey, lead pencil and an eraser. Sharpeners on the tables. (Maps produced individually not as group)

\section{INSTRUCTIONS (5 MINUTES):}

1. Thank you for completing the preliminary questionnaire. Now we have another exercise to complete before the game.

2. The purpose of this exercise is to draw maps that illustrate your 'mental models' or in other words, your thinking about the health of Arctic ecosystems.

3. Don't worry if you feel you don't know enough about the Arctic to produce such a map. This is not about being 'right' or 'wrong'. We are interested in what you know and think.

Also: don't worry if you don't know how to draw maps showing this kind of information. I'll be guiding you through this process step-by-step so that you can produce your own map.

Before we begin, here is an example of the kind of map you will be producing.

SHOW EXAMPLE OF MENTAL MODEL MAP (see figure below)

\section{Example of a mental model map}

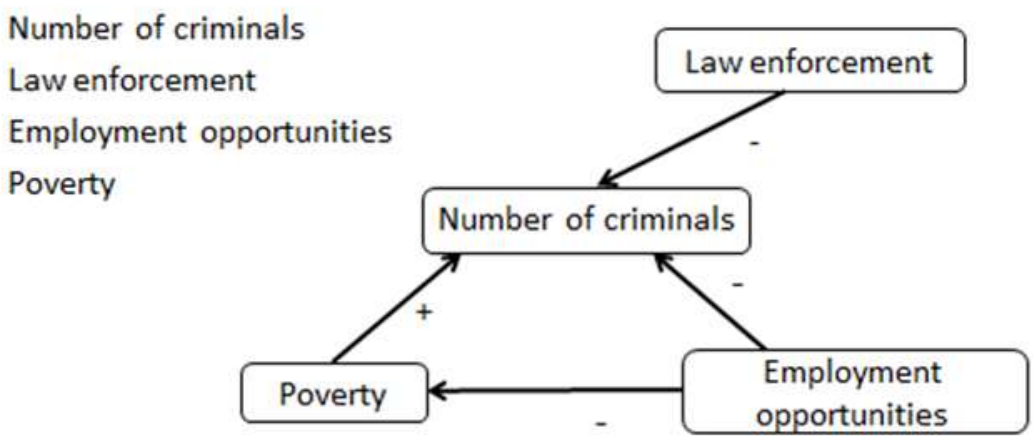


4. This is an example of a map representing a person's thinking about crime in their neighborhood. Note that this is a hypothetical example that we are using to exemplify how one person might represent their thinking about a particular issue.

As you can see, this hypothetical person considered that the key issues relating to crime in their neighborhood were: [read out list on top left]. The diagram on the right shows how this individual perceived the relationships between these different factors.

GO THOUGH MAP AND EXPLAIN STEP-BY-STEP

Any questions? (Clarify all questions - make note of all questions asked)

Let us begin.

MAPPING (15-20 MINUTES):

(Selection of key concepts by participants)

ASK THEM TO USE LEAD PENCIL ONLY

1. When I mention the Arctic marine and sea-ice ecosystems, including the species and inhabitants of these ecosystems, what does it make you think of? What aspects, issues or concepts come to mind?

2. Please list down the left hand side of the paper provided all the different concepts or aspects that come to mind when you think of the Arctic marine and sea-ice ecosystem.

Your concepts can be simple words or nouns (such as "fish" in the example I showed you), or more complex concepts, such as "trout populations in the summer".

Wait for participants to write list of concepts, until they start slowing down.

3. Now I want you to think about all the factors that affect negatively affect the health of Arctic marine and sea-ice ecosystems positively, its species and inhabitants.

List all these factors on the left side of your paper straight underneath the previous list.

If you find you have already listed factors that negatively affect the health of the Arctic, that is fine. There is no right or wrong in what you think is important.

Wait for participants to write list of concepts, until they start slowing down.

4. Now I want you to think about all the factors that affect positively affect the health of Arctic marine and sea-ice ecosystems positively, its species and inhabitants.

List all these factors on the left side of your paper straight underneath the previous list.

Wait for participants to write list of concepts, until they start slowing down. 
(Mapping begins).

5. Great. Now the mapping begins.

1) Firstly, please select one concept from your list that you feel is the most important in relation to the health of the Arctic, and write it down somewhere in the middle of your sheet of paper.

Wait for participants to write central concept

2) Now select a concept from your list that you feel strongly influences or is influenced by this central concept and write it on the paper near to the central concept.

Wait for participants to write next concept

3) Draw an arrow connecting the two concepts. The direction of the arrow will indicate the direction of the relationship.

Wait for participants to draw arrow

4) Now indicate next to the arrow whether you think this relationship is +ve or -ve. Simple write "+" or "_" alongside the arrow.

Wait for participants to add sign

5) Now select another concept from your list that influences or is influenced by any of the concepts on your map.

Wait for participants to complete this

6) Write it on the paper.

7) Link the concepts with arrows. Indicate a plus or minus sign next to the arrow.

8) And so on.

**You are not restricted to the list of concepts you generated at the beginning. If you realize something is missing, please add it in as you draw your map.

**You may alter your map as you go, change arrow directions and so forth, until you are happy with the final map. Please take your time.

If you have any questions, please ask!

\section{Wait for participants to complete their maps}

(Weighting the influences)

9) Once you have a map that you are content with, I will ask you to indicate the strength of the relationship between concepts. You will do this by writing a number from 1 to 
3 alongside the arrows, where 1 indicates a weak relationship, 2 indicates a medium strength relationship and 3 indicates a strong relationship.

** You may alter your map as you go, change arrow directions and strengths of relationships and so forth, until you are happy with the final map. Please take your time.

(Final remarks as people are finishing up)

6. When you are happy with your final map, and you feel it represents your thinking about the health of the Arctic marine and sea-ice ecosystems, please put your pencils down so I can collect your map. If you need to clarify anything about your map, please do so then. Thanks!

When everyone else has finished:

WE CAN MOVE ON TO THE NEXT PART.

\section{Part 2: POST-intervention/control (slight difference between game \& control groups)}

\section{$\underline{\text { Facilitator Guide }}$}

Participants' previously drawn cognitive maps are returned to them; also given a colored pencil (no erasers!) NB: colored pencil used to distinguish from plain lead pencil used for Part I.

READ OUT ALL NON-ITALICIZED TEXT:

5. As you can see, I have returned your original maps to you. Remember that these maps illustrate your thinking about the health of Arctic marine and sea-ice ecosystems.

6. Now I am going to ask you to examine your maps, and based on what you might have learned from [playing Eco-chains/the article you just read], adjust them accordingly. For example:

7. If you wish to delete anything, please put a neat line through it. Don't rub it out! We are interested in what you thought before you played the game.

8. Please adjust your map as you see fit, until you are happy with the final map. Please take your time.

If you have any questions, please ask! (Adjusting maps (10 minutes))

Wait for participants to work on their maps, until they start slowing down.

(Final remarks as people are finishing up)

9. When you are happy with your final map, and you feel it represents your thinking about the health of the Arctic marine and sea-ice ecosystems, please put your pencils down. If you need to clarify anything about your map, please do so then. Thanks! 
Appendix 2. Control (article) text

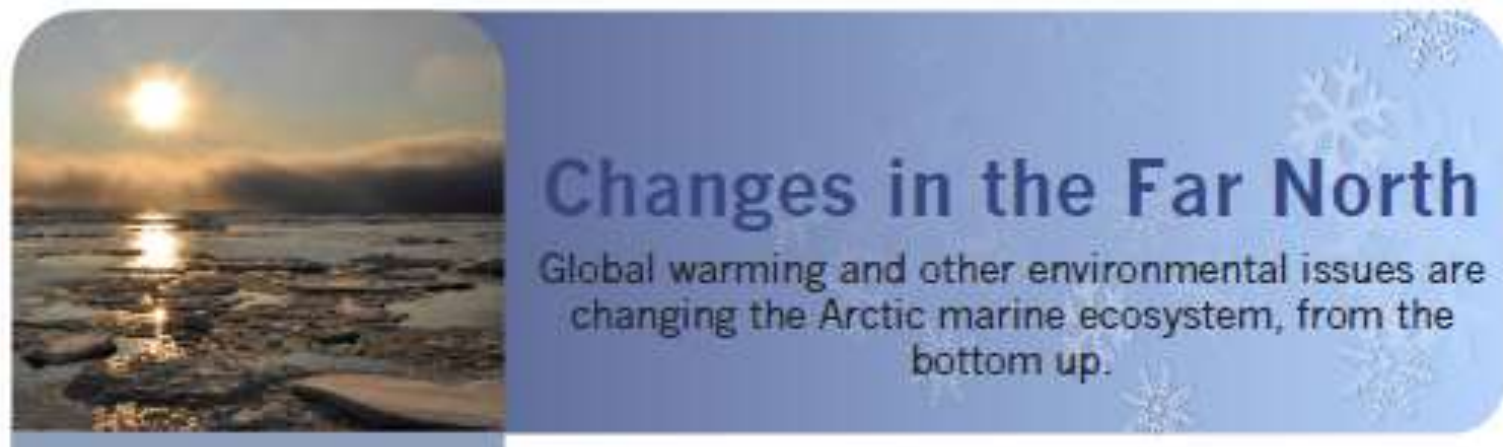

Species Associated

with Arctic Sea lce

Ice Algae

lce al sale are primacy producers

that Erow directly on the

unders de of sea ice.

Ice Copepod

The bodies of lce copepod are up to $70 \%$ fat which helps them survive the long Arctic winter

\section{Arctic Cod}

Sea ice containe nooks and

crannies that provide the Arctic

Cod ratuse from predators

\section{Ringed Seal}

Ringed seals spend much of their

ives on sea loe, siving birth and

raising pups in dens under the

snow:

\section{Walrus}

Walrus heft their lares bodies:up to $1,900 \mathrm{~kg}$, on to sea ice to rest and drift to new feeding grounds.

\section{Polar Bears}

Polar bears, hishly dependent on sed ice, are threstened by alobal waming due to loss of habitht and prey

\section{Human Beings}

Subsistence huntangrand fishing plays a key role in the way of life: for many Arotic Indigenous: peoples, who use ses ice as ia: hontina platoorm
The Arctic marine ecosystem is special: many of the species are closely linked with sea ice. As global warming progresses and the area of year-round sea ice cover shrinks, the range and quality of ice habitat will also decrease. Over the last 30 years. temperatures have increased almost twice as fast in the Arctic as compared to the rest of the world. Arctic ice and snow are melting so quickly, and polar ecosystems are changing so fast. that Inuit elders have said, "the weather today is harder to know."

For marine mammals that depend on sea ice, its loss is a significant problem. Diminishing sea ice means diminishing habitat for polar bears and ice-dependent seals. Polar bears excavate snow caves to give birth to their cubs; these caves are often on land, but sometimes are dug on sea ice. The polar bear's main prey is the ringed seal, and bears use sea ice as a platform to reach and locate ringed seals. Locating food in the spring is an especially urgent quest for mother polar bears, which have not eaten for half a year by the time their cubs are born.

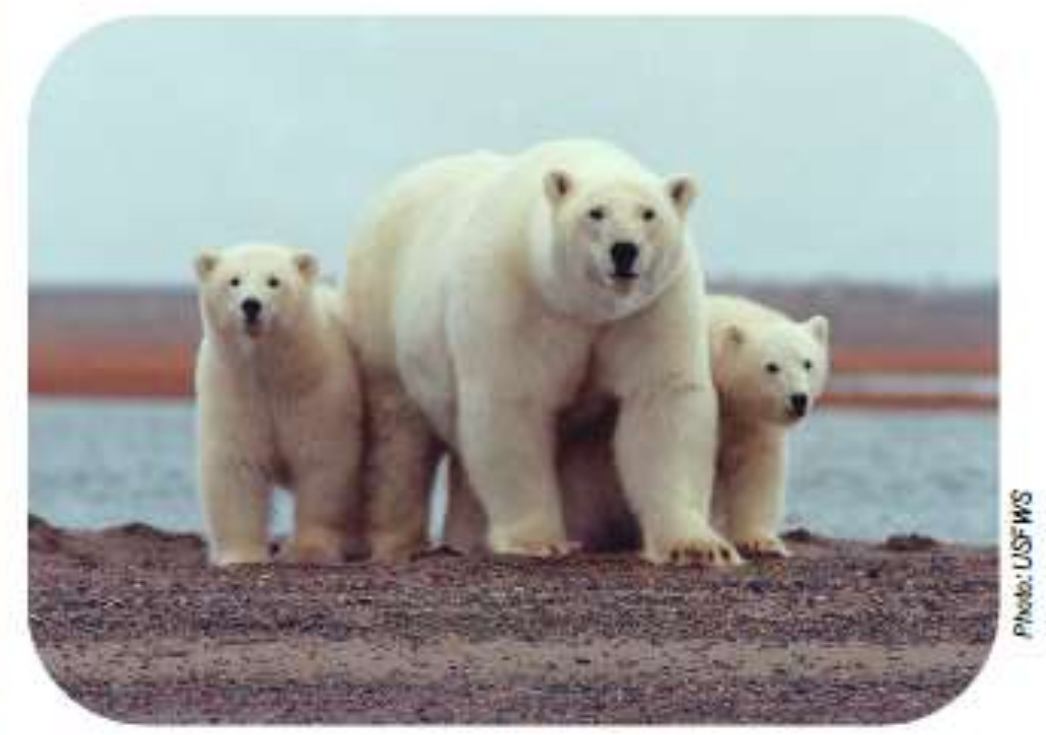

Article adapted by Jessica Brunacini from Stephanie Pliman, "Changes in the North" in Climate Change: Picturing the Science (pgs. 45-69), by G. Schmidt and J. Wolle, 2008, New York; W.W. Norton \& Company. 


\section{Changes in the Far North}

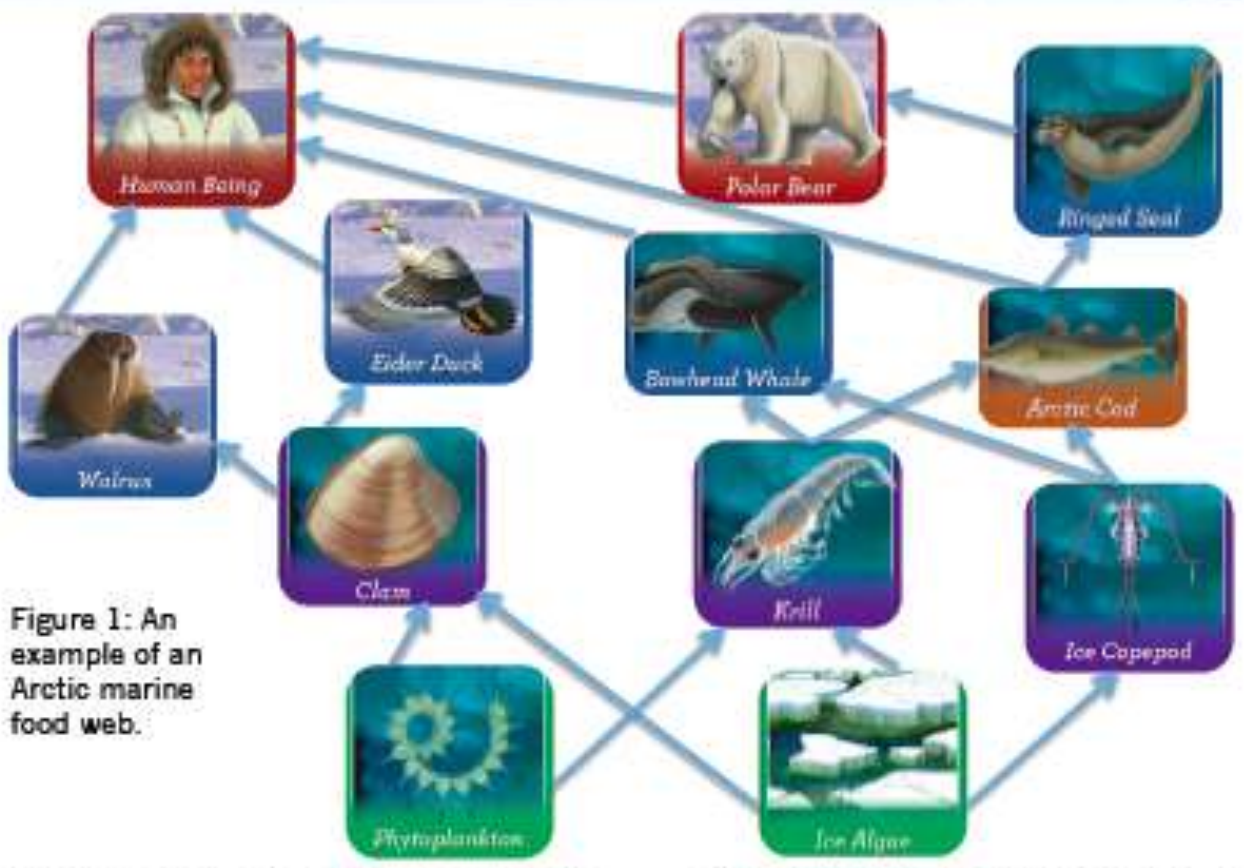

Ringed seals also breed on the sea ice in snow lairs. When the snow is not thick enough to support a seal lair through the winter, the seal pups can be exposed to the cold and die. Unstable sea ice that breaks up prematurely also forces young ringed seals into the water too early to be reared properly, and they do not survive.

These changes in sea ice will affect not just the seals and polar bears, but will have consequences for the rest of the ecosystem that depends on them. Of all the marine "country food" in the Arctic, the ringed seal is the most critical for the Inuit, for the same reason that the seal is important to polar bears: it is the most abundant seal species in the Arctic, numbering in the millions. Ringed seals are able to create breathing holes in the densest sea ice using the heavy claws on their foreflippers. Since every seal must breathe, these holes are the best places for a bear or an Inuit to hunt for one, even during difficult ice conditions when little other food is available.

Changing ecosystems in the sea also affect ecosystems on land. Consider the marginal ice zone, where drifting pack ice encounters open water. This border is an area of high productivity during the spring because nutrients, buit up in surface waters under the ice during the long winter, are finally exposed to sunlight. The combination of sunlight and nutrients culminates in a burst of algae blooms from April through May: ice algae grow on the underside of sea ice and phytoplankton in the surface waters. The algae are eaten by a variety of zooplankton, such as ice copepod and krill, which in turn are fed on by fish like the Arctic cod and seabirds like the ivory gull. Springtime productivity in the marginal ice zone is so high, in fact, that birds and whales migrate thousands of kilometers from all over the globe to feed here. And we do, too: Arctic fisheries, including the Barents and the Bering seas, are among the most productive in the world, providing about 10 percent of the world catch. Alaskan fisheries alone provide more than half of the fish caught in U.S. waters.

Biological activity during the spring bloom is so intense because much of the food is kept floating in the upper part of the water column due to the density stratification caused by melting ice. This freshwater melt makes the surface layer less dense than the more salty water beneath. It is like adding pepper and other spices to an oil and vinegar salad dressing: the species settle through the top layer of oil and then remain there at the interface along the top of the vinegar. But because so much food is produced in the ocean during the spring bloom, not all of it can be eaten right away. and some settles to the sea floor. In shallow regions, the rain of food supports bottom-dwelling organisms, such as clams, and other species that feed from the sea floor, including walrus and bearded seals, who use prominent whiskers to feel along the soft bottom sediment for prey. 


\section{Changes in the Far North}

Arctic whales, such as narwhais, belugas, and bowheads, migrate along the edge of the pack ice, moving north when it retreats in summer and south as it extends in the winter. Whales in and around ice-covered waters need to find open spaces between floes, or along their edges, where they can come to the surface to breathe. The bowhead whale, however, can break through up to 61 centimeters of ice cover with its head to make a small breathing hole. Like the Arctic whales, many seabirds are local; the ivory gull, for instance, spends the entire year in the region. In the Arctic, seabirds nest on land, along cliffs (to escape predators), or on the ground, but they fly to sea to forage along the edges of the sea ice and in other places where prey is concentrated by ocean currents. Ivory gulls and eider ducks often dive underwater to catch their food.

Climate change is not the only environmental stress on the Arctic - the transport of pollutants from areas further south is also a concern. Despite the remoteness of the Arctic and its seemingly pristine condition, agricultural and industrial pollutants are transported north with the same winds that bring heat from the tropics. Once there, the contaminants move through the physical and biological system. Because some chemicals, such as PCBs and insecticides, attach to fat and do not degrade easily, they wind up accumulating at the top of the food chain - and you are what you eat. As a result, polar bears in Greenland and other regions of the Artic have such high levels of contaminants in their bodies that their reproductive ability may be impaired. Combining this toxic load with difficulties in obtaining prey due to climate change may be the downfall of some high-level Arctic organisms, including sea birds and polar bears: as animals starve, they draw down on reserves of fat, and if it is loaded with contaminants, this will exacerbate health problems. Eating contaminated organisms also exposes Arctic people to health risks: blood samples from a number of residents of eastern Canada, Greenland, and eastern Siberia have indicated elevated levels of persistent organic pollutants such as PCBs and the insecticide DDT.

Another potential pressure on the Arctic marine ecosystem is overharvesting. Overharvesting occurs when larger numbers of species are killed than the population can replace through natural reproduction. Hunting and fishing play a crucial role in the subsistence life ways of many Arctic Indigenous communities. As global warming and other environmental issues continue to impact the Arctic marine ecosystem, the added pressure of hunting and fishing could undermine the population health and sustainability of species on which Native communities depend. There are ways to protect at-risk populations of species, however. Legislation can manage hunting and fishing through the use of community- and ecosystem-based management that closely monitors populations and sets sustainable harvesting quotas. Marine protected areas can also be established to protect some or all of the species in a designated area from being harvested. possibly allowing populations to recover.

One small change can have a significant impact throughout the Arctic marine ecosystem, making it especially sensitive to the effects of global warming and other environmental challenges. Human actions, both near and far, affect these unique species and the habitat in which they live.

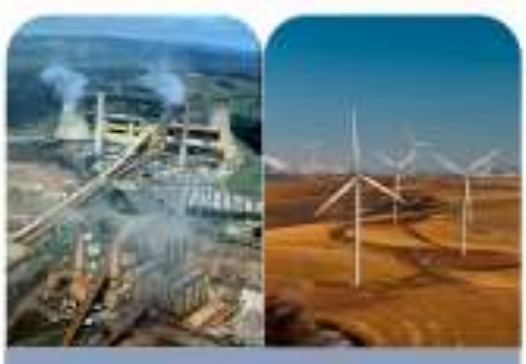

Global Warming

When coal. oil, and ges fossil fuals) are burned to. produce enaray and alectricity, thay release carbon poliution that contributes to global warming The use of fositil fuel eneray for the predictern and disfibution of consumer goods creates carbon poilution: Homes and businessea abo use larco amounts of fossil fues enerey for heating cooling and lisiting needs carbon pollution from cars, tricks, SUVs and other passenger vahicles is increasing as more people around the worid choose to drive. Increasing carton pollution and global warmine reduce the amount of Arotic sed ice.

Luckily, thereis are actions tha: people can take to cembat riobal waming Solar, wind, goothermal. and nuciear enera sources can be used to produse eneray and electricity that heips preyent global waming: Manufacturers can cut down on carbon poilution by switching to renewable energy incressing energy efficiency and using recycled materalis Homes and businesses can also use less eneray uhen building insulation is improved and enerey efficient applances and products areused lastly, wakins, biking carpooling and using public transportation can he $p$ combat glotal wamsing by cutting down on carbon pollution. Reducing new carbon polution. as well as trapping and stoning existing carbon pollution slows and possibly reverses global wamine. Which allows for the restoration of Arctic sea ice 
Appendix 3: Impact of game and article (control) on FCM indices (within-group)

Table A3.1 Impact of game and article on structural indices. Figures in parentheses are standard deviations

\begin{tabular}{lcccccc}
\hline & \multicolumn{3}{c}{ Control $(\mathrm{n}=20)$} & \multicolumn{3}{c}{ Treatment (n=21) } \\
& Map1 & Map 2 & p-value & Map 1 & Map 2 & p-value \\
\hline Number of concepts & 9.15 & 13.9 & $0.000^{*}$ & 8.67 & 11.23 & $0.000^{*}$ \\
& $(2.70)$ & $(3.32)$ & & $(2.78)$ & $(3.43)$ & \\
Number of & 13.7 & 26.25 & $0.000^{*}$ & 11.33 & 15.81 & $0.000^{*}$ \\
connections & $(5.67)$ & $(9.75)$ & & $(5.18)$ & $(6.11)$ & \\
Ratio of connections & 1.48 & 1.86 & $0.001^{*}$ & 1.31 & 1.41 & 0.096 \\
to nodes & $(0.39)$ & $(0.54)$ & & $(0.41)$ & $(0.31)$ & \\
Density & 0.08 & 0.03 & $0.000^{*}$ & 0.11 & 0.06 & $0.004^{*}$ \\
& $(0.07)$ & $(0.04)$ & & $(0.09)$ & $(0.03)$ & \\
Number of & 1.8 & 2.3 & 0.086 & 1.86 & 2.62 & $0.019^{*}$ \\
transmitter concepts & $(1.06)$ & $(1.38)$ & & $(1.31)$ & $(1.99)$ & \\
Number of receiver & 1.95 & 2.65 & $0.047^{*}$ & 1.90 & 2.37 & 0.366 \\
concepts & $(1.67)$ & $(1.87)$ & & $(1.39)$ & $(1.68)$ & \\
Number of & 0.15 & 0.30 & 0.523 & 0.42 & 0.42 & 1.000 \\
unconnected nodes & $(0.67)$ & $(0.73)$ & & $(0.98)$ & $(0.81)$ & \\
\hline
\end{tabular}
$* \mathrm{p}<0.05$ 
Table A3.2 Impact of game and article on centrality for concept categories. Figures in parentheses are standard deviations

\begin{tabular}{lcccccc}
\hline & \multicolumn{3}{c}{ Control (n=20) } & \multicolumn{3}{c}{ Treatment (n=21) } \\
Concept Categories & Map 1 & Map 2 & p-value & Map 1 & Map 2 & p-value \\
\hline Ice & 3.12 & 4.29 & 0.1283 & 2.15 & 2.95 & 0.1402 \\
& $(1.82)$ & $(2.34)$ & & $(1.37)$ & $(2.03)$ & \\
Base food chain & 0.67 & 2.64 & $0.0147^{*}$ & 2.00 & 2.30 & 0.7306 \\
& $(0.58)$ & $(1.16)$ & & $(1.76)$ & $(1.16)$ & \\
Mid-level food chain & 2.29 & 4.29 & 0.0948 & 1.56 & 2.06 & 0.4408 \\
& $(1.80)$ & $(2.50)$ & & $(1.17)$ & $(0.59)$ & \\
Birds & 1.84 & 2.66 & 0.1900 & 0.67 & 0.00 & - \\
& $(0.33)$ & $(1.12)$ & & $(0.00)$ & $(0.00)$ & \\
Mammals & 2.06 & 3.18 & $0.0241^{*}$ & 1.30 & 1.43 & 0.6699 \\
& $(1.10)$ & $(1.74)$ & & $(0.68)$ & $(0.74)$ & \\
Humans in Arctic & 3.33 & 2.85 & 0.6729 & 1.67 & 1.67 & 1.0000 \\
& $(1.76)$ & $(2.07)$ & & $(1.30)$ & $(1.07)$ & \\
Biodiversity other & 2.70 & 4.04 & 0.1207 & 2.85 & 2.72 & 0.8511 \\
& $(1.48)$ & $(2.20)$ & & $(1.54)$ & $(1.87)$ & \\
Environmental problems & 2.65 & 3.20 & 0.0655 & 2.15 & 2.42 & 0.2752 \\
& $(1.49)$ & $(1.96)$ & & $(1.20)$ & $(1.67)$ & \\
Human actions causing & 1.85 & 2.34 & 0.1867 & 1.65 & 1.97 & 0.2293 \\
environ problems & $(0.80)$ & $(1.63)$ & & $(1.03)$ & $(0.97)$ & \\
Actions to protect Arctic & 1.71 & 2.11 & 0.3219 & 2.05 & 2.06 & 0.9515 \\
& $(1.24)$ & $(1.59)$ & & $(1.41)$ & $(1.34)$ & \\
Climate system & 2.41 & 3.24 & 0.1933 & 2.08 & 2.56 & 0.5674 \\
& $(1.29)$ & $(1.86)$ & & $(0.83)$ & $(1.43)$ & \\
Other & 1.28 & 1.57 & 0.2354 & 1.87 & 0.90 & 0.0752 \\
& $(0.39)$ & $(0.46)$ & & $(0.87)$ & $(0.81)$ & \\
\hline
\end{tabular}

$* \mathrm{p}<0.05$ 
Table A3.3 Impact of game and article on outdegree for concept categories. Figures in parentheses are standard deviations

\begin{tabular}{lcccccc}
\hline & \multicolumn{3}{c}{ Control (n=20) } & \multicolumn{3}{c}{ Treatment (n=21) } \\
Broad Concept & Map 1 & Map 2 & p-value & Map 1 & Map 2 & p-value \\
\hline Ice & 1.57 & 2.70 & 0.0560 & 1.13 & 1.61 & 0.2364 \\
& $(1.32)$ & $(1.80)$ & & $(0.93)$ & $(1.56)$ & \\
Base food chain & 0.11 & 1.15 & 0.0733 & 0.89 & 0.73 & 0.7523 \\
& $(0.19)$ & $(1.22)$ & & $(0.84)$ & $(0.73)$ & \\
Mid-level food chain & 0.67 & 1.96 & 0.0674 & 0.22 & 0.87 & 0.1927 \\
& $(0.75)$ & $(1.58)$ & & $(0.39)$ & $(0.69)$ & \\
Birds & 0.00 & 0.00 & - & 0.00 & 0.00 & - \\
& $(0.00)$ & $(0.00)$ & & $(0.00)$ & $(0.00)$ & \\
Mammals & 0.20 & 0.53 & 0.0760 & 0.03 & 0.16 & 0.1598 \\
& $(0.39)$ & $(0.64)$ & & $(0.10)$ & $(0.26)$ & \\
Humans in Arctic & 2.08 & 0.78 & 0.1051 & 0.58 & 0.71 & 0.7393 \\
& $(1.95)$ & $(1.26)$ & & $(0.50)$ & $(0.65)$ & \\
Biodiversity other & 0.78 & 1.24 & 0.4918 & 0.41 & 0.39 & 0.9212 \\
Environmental problems & $(1.28)$ & $(1.70)$ & & $(0.49)$ & $(0.59)$ & \\
& 1.39 & 1.70 & 0.2058 & 1.09 & 1.24 & 0.3985 \\
Human actions causing & $(1.25)$ & $(1.60)$ & & $(0.91)$ & $(1.22)$ & \\
environ problems & 1.28 & 1.63 & 0.2741 & 1.06 & 1.20 & 0.5494 \\
Actions to protect Arctic & $(0.71)$ & $(1.45)$ & & $(0.95)$ & $(0.82)$ & \\
& 1.37 & 1.68 & 0.4427 & 1.30 & 1.41 & 0.7005 \\
Climate system & $(1.15)$ & $(1.58)$ & & $(1.15)$ & $(1.22)$ & \\
& 1.33 & 1.81 & 0.4119 & 1.92 & 1.72 & 0.7848 \\
Other & $(1.26)$ & $(1.68)$ & & $(0.83)$ & $(1.24)$ & \\
& 0.72 & 1.10 & 0.2723 & 1.47 & 0.48 & 0.0872 \\
\hline
\end{tabular}


Table A3.4 Impact of game and article on indegree for concept categories. Figures in parentheses are standard deviations

\begin{tabular}{lcccccc}
\hline & \multicolumn{3}{c}{ Control (n=20) } & \multicolumn{3}{c}{ Treatment (n=21) } \\
Broad Concept & Map 1 & Map 2 & p-value & Map 1 & Map 2 & p-value \\
\hline Ice & 1.55 & 1.60 & $0.0432^{*}$ & 1.02 & 1.35 & $0.0386^{*}$ \\
& $(0.69)$ & $(1.00)$ & & $(0.80)$ & $(0.97)$ & \\
Base food chain & 0.56 & 1.49 & 0.0633 & 1.11 & 1.57 & 0.0572 \\
& $(0.50)$ & $(0.78)$ & & $(0.96)$ & $(1.11)$ & \\
Mid-level food chain & 1.62 & 2.33 & $0.0179^{*}$ & 1.33 & 1.20 & 0.3861 \\
& $((1.38)$ & $(1.39)$ & & $(1.25)$ & $(0.96)$ & \\
Birds & 1.84 & 2.52 & 0.2152 & 0.67 & 0.00 & - \\
Mammals & $(0.33)$ & $(1.11)$ & & $(0.00)$ & $(0.00)$ & \\
& 1.86 & 2.65 & $0.0000^{*}$ & 1.27 & 1.28 & 0.4302 \\
Humans in Arctic & $(1.02)$ & $(1.39)$ & & $(0.68)$ & $(0.78)$ & \\
& 1.25 & 2.08 & 0.2349 & 1.08 & 0.95 & 0.3910 \\
Biodiversity other & $(1.89)$ & $(2.08)$ & & $(0.96)$ & $(0.99)$ & \\
Environmental problems & 1.93 & 2.80 & $0.0054^{*}$ & 2.44 & 2.33 & 0.1424 \\
& $(1.92)$ & $(1.96)$ & & $(1.69)$ & $(2.02)$ & \\
Human actions causing & 1.25 & 1.50 & $0.0000^{*}$ & 1.06 & 1.18 & $0.0178^{*}$ \\
environ problems & $(1.25)$ & $(1.01)$ & & $(0.80)$ & $(0.98)$ & \\
Actions to protect Arctic & 0.58 & 0.71 & 0.1342 & 0.59 & 0.77 & $0.0222^{*}$ \\
& $(0.59)$ & $(0.66)$ & & $(0.61)$ & $(0.71)$ & \\
Climate system & 0.35 & 0.44 & 0.0573 & 0.75 & 0.65 & 0.5912 \\
& $(0.54)$ & $(0.55)$ & & $(0.89)$ & $(0.77)$ & \\
Other & 1.08 & 1.43 & 0.1234 & 0.17 & 0.84 & 0.2517 \\
& $(0.74)$ & $(0.42)$ & & $(0.34)$ & $(0.84)$ & \\
& 0.56 & 0.48 & - & 0.40 & 0.43 & 0.8170 \\
\hline
\end{tabular}

${ }^{*} \mathrm{p}<0.05$ 
Appendix 4. Comparing FCM indices between game and article groups before intervention

Table A4.1

\begin{tabular}{|c|c|c|c|c|}
\hline & $\begin{array}{c}\text { Control } \\
\text { Map } 1(\mathrm{n}=20)\end{array}$ & $\begin{array}{c}\text { Treatment } \\
\text { Map } 1(n=21)\end{array}$ & $\begin{array}{l}\text { (Unpaired) t- } \\
\text { test p-value }\end{array}$ & $\begin{array}{l}\text { Mann Whitney } \\
\text { test p-value }\end{array}$ \\
\hline Number of concepts (N) & $\begin{array}{l}9.15 \\
(2.70)\end{array}$ & $\begin{array}{c}8.67 \\
(2.78)\end{array}$ & 0.5759 & 0.4927 \\
\hline $\begin{array}{l}\text { Number of connections } \\
\text { (C) }\end{array}$ & $\begin{array}{l}13.7 \\
(5.67)\end{array}$ & $\begin{array}{l}11.33 \\
(5.18)\end{array}$ & 0.1704 & 0.1254 \\
\hline $\begin{array}{l}\text { Ratio of connections to } \\
\text { nodes }(\mathrm{C} / \mathrm{N})\end{array}$ & $\begin{array}{l}1.48 \\
(0.39)\end{array}$ & $\begin{array}{c}1.31 \\
(0.41)\end{array}$ & 0.1687 & 0.1705 \\
\hline Density & $\begin{array}{c}0.08 \\
(0.07)\end{array}$ & $\begin{array}{c}0.11 \\
(0.09)\end{array}$ & 0.2065 & 0.1144 \\
\hline $\begin{array}{l}\text { Number of receiver } \\
\text { concepts }\end{array}$ & $\begin{array}{c}1.95 \\
(1.67)\end{array}$ & $\begin{array}{l}1.90 \\
(1.39)\end{array}$ & 0.8341 & 0.7531 \\
\hline $\begin{array}{l}\text { Number of transmitter } \\
\text { concepts }\end{array}$ & $\begin{array}{c}1.8 \\
(1.06)\end{array}$ & $\begin{array}{l}1.86 \\
(1.31)\end{array}$ & 0.8792 & 0.9782 \\
\hline $\begin{array}{l}\text { Number of unconnected } \\
\text { nodes }\end{array}$ & $\begin{array}{c}0.15 \\
(0.67)\end{array}$ & $\begin{array}{c}0.42 \\
(0.98)\end{array}$ & 0.2965 & 0.1908 \\
\hline
\end{tabular}


Appendix 5. Concept codes

\begin{tabular}{|l|c|l|}
\hline Concepts (NODES) & Code & Categories level2 \\
\hline ice & 100 & Ice (code 1) \\
\hline sea ice & 101 & Ice (code 1) \\
\hline ice thickness & 102 & Ice (code 1) \\
\hline ice melting & 103 & Ice (code 1) \\
\hline iceberg & 104 & Ice (code 1) \\
\hline iceberg melting/ decreasing & 105 & Ice (code 1) \\
\hline glaciers & 106 & Ice (code 1) \\
\hline $\begin{array}{l}\text { primary producers/ base of food } \\
\text { chain }\end{array}$ & 200 & Base food chain (code 2) \\
\hline ice algae & & \\
\hline phytoplankton & 201 & Base food chain (code 2) \\
\hline seaweed & 202 & Base food chain (code 2) \\
\hline zooplankton & 221 & Base food chain (code 2) \\
\hline krill & 210 & Base food chain (code 2) \\
\hline ice copepod & 211 & Base food chain (code 2) \\
\hline plankton & 212 & Base food chain (code 2) \\
\hline clam & 220 & Base food chain (code 2) \\
\hline squid & 301 & Mid-level food chain (code 3) \\
\hline fish & 302 & Mid-level food chain (code 3) \\
\hline arctic cod/ cod & 310 & Mid-level food chain (code 3) \\
\hline birds & 311 & Mid-level food chain (code 3) \\
\hline penguins & 400 & Birds (code 4) \\
\hline eider ducks & 401 & Birds (code 4) \\
\hline ivory gull & 402 & Birds (code 4) \\
\hline marine mammals & 403 & Birds (code 4) \\
\hline polar bear & 500 & Marine mammals (code 5) \\
\hline walrus & 501 & Marine mammals (code 5) \\
\hline seals & 502 & Marine mammals (code 5) \\
\hline bearded seal & 510 & Marine mammals (code 5) \\
\hline ringed seal & 511 & Marine mammals (code 5) \\
\hline whales & 512 & Marine mammals (code 5) \\
\hline beluga whale & 520 & Marine mammals (code 5) \\
\hline bowhead whale & 521 & Marine mammals (code 5) \\
\hline gray whale & 522 & Marine mammals (code 5) \\
\hline narwhal & 523 & Marine mammals (code 5) \\
\hline humans in arctic & 524 & Marine mammals (code 5) \\
\hline & 530 & Humans in Arctic (code 5.3) \\
\hline & \\
\hline
\end{tabular}




\begin{tabular}{|c|c|c|}
\hline eskimos/indigenous & 531 & Humans in Arctic (code 5.3) \\
\hline biodiversity & 600 & Other biodiversity Arctic (code 6) \\
\hline native species & 550 & Other biodiversity Arctic (code 6) \\
\hline ecosystem & 601 & Other biodiversity Arctic (code 6) \\
\hline healthy (arctic) ecosystem & 602 & Other biodiversity Arctic (code 6) \\
\hline wildlife/animals & 603 & Other biodiversity Arctic (code 6) \\
\hline arctic animals/species & 605 & Other biodiversity Arctic (code 6) \\
\hline $\begin{array}{l}\text { food chain/relationship between } \\
\text { animals }\end{array}$ & 606 & Other biodiversity Arctic (code 6) \\
\hline bears & 533 & Other biodiversity Arctic (code 6) \\
\hline sea lions & 534 & Other biodiversity Arctic (code 6) \\
\hline global warming/ cc/ getting warmer & 700 & Environmental problems (code 7) \\
\hline increase ocean temperature & 701 & Environmental problems (code 7) \\
\hline changing ocean water temperature & 702 & Environmental problems (code 7) \\
\hline greenhouse gases & 710 & Environmental problems (code 7) \\
\hline carbon pollution/ co2 & 711 & Environmental problems (code 7) \\
\hline methane & 712 & Environmental problems (code 7) \\
\hline ozone/O3 & 713 & Environmental problems (code 7) \\
\hline ultraviolet & 714 & Environmental problems (code 7) \\
\hline $\begin{array}{l}\text { pollution (generic)/ human } \\
\text { pollution }\end{array}$ & 720 & Environmental problems (code 7) \\
\hline pollution (water or ocean) & 721 & Environmental problems (code 7) \\
\hline pollution (air) & 722 & Environmental problems (code 7) \\
\hline local pollution & 723 & Environmental problems (code 7) \\
\hline pollution (food) & 740 & Environmental problems (code 7) \\
\hline chemicals & 843 & Environmental problems (code 7) \\
\hline water level/ sea level & 730 & Environmental problems (code 7) \\
\hline sea level rise & 731 & Environmental problems (code 7) \\
\hline invasive species/killer whales & 732 & Environmental problems (code 7) \\
\hline $\begin{array}{l}\text { natural disasters (flooding, } \\
\text { hurricanes etc) }\end{array}$ & 733 & Environmental problems (code 7) \\
\hline $\begin{array}{l}\text { changing populations of Arctic } \\
\text { species }\end{array}$ & 604 & Environmental problems (code 7) \\
\hline habitat changes & 607 & Environmental problems (code 7) \\
\hline food shortages & 608 & Environmental problems (code 7) \\
\hline extinction & 609 & Environmental problems (code 7) \\
\hline migration & 610 & Environmental problems (code 7) \\
\hline ocean acidification & 724 & Environmental problems (code 7) \\
\hline
\end{tabular}




\begin{tabular}{|l|c|l|}
\hline fossil fuels (use of/burning) & 800 & $\begin{array}{l}\text { Human activities causing environmental } \\
\text { problems (code 8) }\end{array}$ \\
\hline $\begin{array}{l}\text { emissions (from transport) \& } \\
\text { transport/automobiles }\end{array}$ & 801 & $\begin{array}{l}\text { Human activities causing environmental } \\
\text { problems (code 8) }\end{array}$ \\
\hline heating/cooling/lighting & 802 & $\begin{array}{l}\text { Human activities causing environmental } \\
\text { problems (code 8) }\end{array}$ \\
\hline $\begin{array}{l}\text { manufacturing/ industry/ } \\
\text { factories/businesses }\end{array}$ & 803 & $\begin{array}{l}\text { Human activities causing environmental } \\
\text { problems (code 8) }\end{array}$ \\
\hline energy use & 850 & $\begin{array}{l}\text { Human activities causing environmental } \\
\text { problems (code 8) }\end{array}$ \\
\hline overharvesting & 810 & $\begin{array}{l}\text { Human activities causing environmental } \\
\text { problems (code 8) }\end{array}$ \\
\hline overfishing & 811 & $\begin{array}{l}\text { Human activities causing environmental } \\
\text { problems (code 8) }\end{array}$ \\
\hline hunting & 812 & $\begin{array}{l}\text { Human activities causing environmental } \\
\text { problems (code 8) }\end{array}$ \\
\hline whaling & 813 & $\begin{array}{l}\text { Human activities causing environmental } \\
\text { problems (code 8) }\end{array}$ \\
\hline fishing & 814 & $\begin{array}{l}\text { Human activities causing environmental } \\
\text { problems (code 8) }\end{array}$ \\
\hline oil drilling & 820 & $\begin{array}{l}\text { Human activities causing environmental } \\
\text { problems (code 8) }\end{array}$ \\
\hline mining & 821 & $\begin{array}{l}\text { Human activities causing environmental } \\
\text { problems (code 8) }\end{array}$ \\
\hline oil companies & 822 & $\begin{array}{l}\text { Human activities causing environmental } \\
\text { problems (code 8) }\end{array}$ \\
\hline oil spills & 823 & $\begin{array}{l}\text { Human activities causing environmental } \\
\text { problems (code 8) }\end{array}$ \\
\hline oil leaking from ships & 830 & $\begin{array}{l}\text { Human activities causing environmental } \\
\text { problems (code 8) }\end{array}$ \\
\hline $\begin{array}{l}\text { human activity (generic - } \\
\text { destructive ) }\end{array}$ & 860 & $\begin{array}{l}\text { Human activities causing environmental } \\
\text { problems (code 8) }\end{array}$ \\
\hline $\begin{array}{l}\text { humanan activities causing environmental } \\
\text { problems (code 8) }\end{array}$ \\
\hline alternative/renewable/clean energy & 900 & Actions to protect Arctic (Code 9) \\
\hline energy efficiency & 901 & Actions to protect Arctic (Code 9) \\
\hline green transportation & 902 & Actions to protect Arctic (Code 9) \\
\hline sustainable business & 910 & Actions to protect Arctic (Code 9) \\
\hline laws/ regulation & Actions to protect Arctic (Code 9) \\
\hline environmental laws & Actions to protect Arctic (Code 9) \\
\hline Kyoto protocol & Actions to protect Arctic (Code 9) \\
\hline
\end{tabular}




\begin{tabular}{|l|c|l|}
\hline law enforcement & 913 & Actions to protect Arctic (Code 9) \\
\hline protecting species/ seas/ areas & 914 & Actions to protect Arctic (Code 9) \\
\hline $\begin{array}{l}\text { government incentives green tech/ } \\
\text { cap-and-trade }\end{array}$ & 940 & Actions to protect Arctic (Code 9) \\
\hline land management & 953 & Actions to protect Arctic (Code 9) \\
\hline educational resource (card game) & 956 & Actions to protect Arctic (Code 9) \\
\hline $\begin{array}{l}\text { information/ awareness raising/ } \\
\text { campaign for raising awareness }\end{array}$ & 920 & Actions to protect Arctic (Code 9) \\
\hline education & 921 & Actions to protect Arctic (Code 9) \\
\hline $\begin{array}{l}\text { government spending on awareness } \\
\text { raising }\end{array}$ & 922 & Actions to protect Arctic (Code 9) \\
\hline environmentally-friendly products & 923 & Actions to protect Arctic (Code 9) \\
\hline NGOs/ environmental organization & 924 & Actions to protect Arctic (Code 9) \\
\hline scientific research & 930 & Actions to protect Arctic (Code 9) \\
\hline $\begin{array}{l}\text { human intervention for good } \\
\text { (general) }\end{array}$ & 950 & Actions to protect Arctic (Code 9) \\
\hline climate (arctic climate) & 750 & Climate System (Code 10) \\
\hline density of air & 1000 & Climate System (Code 10) \\
\hline sea flows/ ocean current & 1001 & Climate System (Code 10) \\
\hline temperature & 1002 & Climate System (Code 10) \\
\hline ocean temperature regulation & 1003 & Climate System (Code 10) \\
\hline atmospheric gases (generic) & 1004 & Climate System (Code 10) \\
\hline sea/ ocean & 1005 & Climate System (Code 10) \\
\hline sunlight & 1006 & Climate System (Code 10) \\
\hline darkness & 1007 & Climate System (Code 10) \\
\hline time & 1008 & Climate System (Code 10) \\
\hline seasons & 1009 & Climate System (Code 10) \\
\hline other & & Other (Code 11) \\
\hline tourism & 951 & Other (Code 11) \\
\hline tourism & 842 & Other (Code 11) \\
\hline employment & 952 & Other (Code 11) \\
\hline consistency & 621 & Other (Code 11) \\
\hline mistrust of science & 955 & Other (Code 11) \\
\hline access & 925 & Other (Code 11) \\
\hline connectivity & 926 & Other (Code 11) \\
\hline overpopulation & 620 & Other (Code 11) \\
\hline consumption (Generic) & 815 & Other (Code 11) \\
\hline trade & 841 & Other (Code 11) \\
\hline &
\end{tabular}

